\title{
Dynamic effects of network exposure on equity markets
}

\author{
Mardi Dungey ${ }^{1} \cdot$ Moses Kangogo $^{1} \cdot$ Vladimir Volkov $^{1}$
}

Received: 20 September 2021 / Revised: 16 January 2022 / Accepted: 1 February 2022 /

Published online: 28 February 2022

(c) Crown 2022

\begin{abstract}
We investigate the contribution of network exposure to both shock transmission and absorption. Our data sample comprises 45 economies for the period 1998-2018 to which we apply spatial econometric estimation technique. Our empirical findings show that both network intensity and interconnectedness in the financial system have impact on increasing network exposure. We also demonstrate how to estimate network intensity in the financial system. Our results indicate that an increased network intensity parameter is associated to period when the financial system is under stress. The results show high exposure of the financial system to vulnerabilities. The results suggest the changing market conditions increase the exposures to the financial system. Thus, effective ways to monitor the financial system should be implemented by the policy makers to reduce the chances of financial instabilities.
\end{abstract}

Keywords Financial markets $\cdot$ Financial networks $\cdot$ Financial stability

JEL Classification G15 $\cdot \mathrm{G} 10 \cdot \mathrm{G} 01 \cdot \mathrm{C} 21$

\section{Introduction}

The occurrence of the 2007-2009 global financial crisis still raises concerns to policy makers, regulators and academic researchers. The focus has been to find ways and mechanisms to develop measures to predict distress in financial institution so as

Mardi Dungey passed away just after we completed the draft of this paper.

The authors received no financial support for the research, authorship, and/or publication of this article. The authors are grateful for comments from participants at INFINITI Conference on International Finance 2018 held at University of Sydney, particularly Samuel Vigne.

Moses Kangogo

moses.kangogo@utas.edu.au

1 Tasmanian School of Business and Economics, University of Tasmania, Private Bag 84, Hobart, TAS 7001, Australia 
to limit further destabilization of the global economy. Until recently, there has been growing research focusing on how to predict systemic risks to minimize the recurrence of financial crises, while the importance of understanding how network exposure contributes to the spread of financial distress in the financial system has been largely underestimated. Motivated with increasing uncertainty of the stability of the financial markets, this paper aims at investigating the effect of network exposure to common factors.

With the advances in both technology and globalization in recent years, there has been an increase in size, complexity, interconnectedness and concentration of the financial system. These factors combined make the financial system more vulnerable to a collapse. To ensure stability in the entire financial system, it is important to study how the global financial system is interconnected. In a nutshell, interconnectedness (the key source of systemic risk) helps to assess systemic risk and financial stability (Billio et al., 2010; Cai et al., 2014). To enable effective monitoring conditions, there is need to quantify and measure these financial linkages.

This paper focuses on identifying the effect of interconnectedness in the financial system. This is achieved through examining the cross-border financial linkages using real data. The paper aims to identify the impact of interconnectedness in either absorbing or spreading risks in the financial system. It focuses on the cross-border exposure, aiming at identifying the role played by interconnectedness in propagating shocks across countries, in the period of 1999-2018. The sample period covers different crisis periods which include the global financial crisis of 2007-2009, the European sovereign debt crisis of 2010 and the Chinese stock market crash of 2015.

Different approaches have been used to measure financial networks, systemic risks and interconnectedness. Recent studies on measuring systemic risk show that it was not only the size of the institution that led to the distress in the financial system but also the interconnectedness between institutions (Billio et al., 2012; Dungey et al., 2012). ${ }^{1}$ Contagion rapidly spread the crisis through financial linkages, leading to severe disruption of financial stability in both the United States and globally. The recent financial crisis emphasized the importance of using interconnectedness (defined as a set of relationships and interactions among the financial markets participants) as a proxy in measuring systemic risk. Hautsch et al. (2014) note that both size and interconnectedness of financial institutions determine its systemic relevance.

Although currently there is ongoing research focusing on the interconnectedness of institutions (Diebold \& Yilmaz, 2009, 2012, 2013; Glasserman and Young, 2015; Tonzer, 2015), there is still need to understand whether an increase of financial linkages affect the stability (either weakening or strengthening) of the financial system and the impact of financial interconnectedness to both common factors and contagion. It is also important to assess the resilient nature of financial networks to shocks (both exogenous and endogenous).

Different studies have extended the variance decomposition model proposed by Diebold and Yilmaz (2012) to measure connectedness in across different markets. For example, Giudici et al. (2021) provide a methodology to build a minimum

\footnotetext{
${ }^{1}$ Interconnectedness address the Too Interconnected To Fail (TITF) paradigm.
} 
variance currency basket aimed at assessing contagion spillovers among foreign exchange markets using the variance decomposition model. Giudici and Pagnottoni (2019) extent variance decomposition model to examine the relationships of five major Bitcoin exchange platforms. Giudici and Pagnottoni (2020) also extent the variance decomposition model to a generalized vector error correction framework to investigate return connectedness across eight of the major exchanges of Bitcoin.

Other emerging research have proposed different approaches to predicting systemic risks across different markets. For example, Resta et al. (2020) apply technical analysis on bitcoin market and find trading on daily data is more profitable than going intraday. Peralta and Zareei (2016) use Markowitz framework to construct a network-based investment strategy. Spelta et al. (2021) develop a novel methodology to detect the emergence of crisis and provide early-warning market signals to policy makers. Spelta (2017) introduces a tensor decomposition technique to empirically extract complex relationships from prices' time series. Spelta et al. (2022) propose a dynamical systems theory for non-linear time series forecasting and investment strategy development which correctly make predictions at long time horizons.

Our paper differs from these approaches in measuring dynamic exposures in the financial system. To estimate the network exposure in the financial system, this paper uses spatial economic approach proposed by Anselin (1988). This is innovative way of estimating the intensity of the exposures to vulnerabilities. The network intensity parameter measures the network exposure in the financial system. We use data on equity because of its ability to accurately reflect market conditions and sentiments.

Our work focusing on the dynamic effects of the network exposure on the financial market has the following contributions. First our paper contributes to the existing literature on interconnectedness by using the spatial econometric approach. Previous research has mainly focused on the advance economies however, little attention has focused on emerging economies. This paper aims at identifying network exposure on both advanced and emerging economies. To the best of our knowledge, this is a major piece of work, that utilizes spatial econometric techniques to estimate the network exposure in the financial system.

The key findings of this paper highlight the role of network exposure in increasing vulnerability, with both interconnectedness and network intensity playing key roles in monitoring these exposures. We find high network intensity coefficient to be associated with extreme events. This suggests that high network intensity parameter relates to crisis period. We also find that both interconnectedness and network intensity increase exposures in the financial system. Cautions must be taken by policy makers in regulating and monitoring financial system to avoid re-occurrences of crises.

The remainder of this paper is organized as follows. Section 2 reviews related literature and develops key hypotheses which form the basis for empirical testing. It also introduces the spatial econometric concept. Section 3 discusses the mechanism underlying network exposure to common factors. Section 4 presents the results and the effect of network exposures. Section 5 discusses various methods of estimating the network intensity parameter. Section 6 presents empirical evidence of the 
network intensity parameter. Section 7 outlines the implications of our results, and Section 8 concludes.

\section{Literature review}

Recent studies have shown that a major contributor to the transmission of shocks during crisis such as the GFC (2007-2009) was not only the institution size, but also the institution interconnectedness. Different interpretations of interconnectedness have resulted in the development of various measurement methods. All these measures aim to assess the role and impact of interconnectedness during financial distress.

Recent findings indicate that interconnectedness acts as a channel through which shocks and losses spread to other financial institutions (Glasserman \& Young, 2015, 2016). Other findings show that interconnectedness acts as a 'double edge' by being able to absorb shocks up to certain point and also transmitting them to the financial system after a given threshold is reached (Acemoglu et al., 2015; Cohen-Cole et al., 2012; Gai \& Kapadia, 2010; Tonzer, 2015). Gai and Kapadia (2010) suggested that an increase in connectivity may lower the chance of contagion, but conditional on a default by a given node, an increase in interconnectedness may trigger defaults to other nodes, making the financial system more sensitive to defaults.

With increasing growth in the cross-border financial activities, interconnectedness poses threats to the financial system via increased vulnerability to shocks spreading globally. Minoiu and Sharma (2014) supported the fact that a high degree of interconnectedness triggered the breakdown of financial system during the 2007-2009 GFC. This implies that the more interconnected an institution, the higher the likelihood of risk amplification to the entire system threatening the stability of the economy.

Markose et al. (2012) referred to institutions that are 'too interconnected' as 'super-spreaders' of shocks in the financial system. This means that interconnectedness of financial institutions tends to spread shocks extensively across links, causing instability in the financial system. Gai and Kapadia (2010) showed that degree of interconnectedness has an impact on contagion by acting as a channel through which contagion spreads and shocks amplify. Greater interconnectedness aids in lowering the likelihood of contagion but increases shocks transmission when the financial system experiences difficulties. ${ }^{2}$ Using spatial modeling, Tonzer (2015) assessed whether cross-border linkages have any impact on the stability of interconnected institutions. Though interconnectedness is beneficial in stable conditions, Tonzer (2015) showed that interconnection of financial institution to foreign entities provided a channel for propagating shocks when the system experienced difficulties.

Assessing interconnectedness in financial institutions could serve as an early warning indicator for distress in financial systems. Econometric measures based on Granger causality and principal components analysis proposed by Billio et al. (2012)

\footnotetext{
${ }^{2}$ See Acemoglu et al. (2015), Gai and Kapadia (2010) and Glasserman and Young (2015) for more details.
} 
measure interconnectedness. These measures show that an increase in links in a financial institution before a crisis signal an early warning. In addition, Minoiu et al. (2015) focused on determining whether interconnectedness in financial institution is a possible source of systemic risk that could serve as an early warning of crisis. Their findings suggested that interconnectedness has early warning indicator properties for a crisis. Diebold and Yilmaz $(2009,2012)$ proposed new measures of interconnectedness by measuring risk and management in financial institutions based on variance decomposition. Their results showed that global financial interconnectedness is time-varying, implying that network exposure within financial institutions varies over time.

Minoiu et al. (2015) showed that an increase in linkages within a country and a decrease in cross-border linkages are associated with a high chance of financial crisis. This is consistent with the results of Peltonen et al. (2019) which indicated that more interbank linkages increase the chance of banking crises. The increase in cross-border transactions led to more interactions and relationships between different markets, leading to the formation of international 'robust-yet-fragile' financial networks. A financial network is 'robust-yet-fragile' when it serves as a shock absorber (promoting financial stability) up to a certain point, beyond which it amplifies shocks (leading to financial instability) in the whole financial system. While financial markets benefit through the formation of more robust and stronger interconnections beyond a certain point, they also create potential channels of shock transmission.

Several studies have explored roles that financial networks play in good and bad periods. The first strand of literature relates interconnectedness to risk diversification, cross-border investment opportunities and availability of different financial products in the market. A financial network is robust when it absorbs shocks, enhancing the stability and health of a financial system (Allen \& Gale, 2000). Having more interconnections implies more risk-sharing and diversification, so shocks hitting the network will be shared among the various interconnected institutions building a resilient financial system (Glasserman \& Young, 2016). This mechanism is supported by Vitali et al. (2016), who found that an increase in interconnections makes the financial system more resilient and increases shock diversification. Other studies show that formation of these interlinkages helps absorb shocks to a certain point before contributing to their spread (Acemoglu et al., 2015; Cohen-Cole et al., 2012; Gai \& Kapadia, 2010; Tonzer, 2015). Kubelec and Sá (2012) argued that financial interconnectedness increases due to countries becoming more open, therefore causing the entire network to collapse. While Gai and Kapadia (2010) determined that stronger connectivity in the financial sector would improve absorption of shocks, they also suggested that conditional on the default of an institution, an increase in network connectivity propagates shocks from one institution to others.

The second strand of literature focuses on how interconnectedness enhances the channels through which shocks spread and intensify to the broader financial system (Battiston \& Caldarelli, 2013; Glasserman \& Young, 2015, 2016). That is, financial networks tend to be fragile when they amplify shocks rather than contain them. This may destabilize the entire financial system by increasing systemic risk, leading to financial instability. Many studies show the extent to which interconnectedness could 
have a negative effect on financial stability. For instance, Battiston and Caldarelli (2013) demonstrated that although individual institutions benefit from increased interlinkages, this could be a channel through which contagion and distress spread to the entire financial system. Battiston et al. (2012) found that an increase in financial interconnections increased credit exposure which increases systemic risk. Amini et al. (2016) argued that institutions with more interconnections contribute more to financial instability. Further, Acemoglu et al. (2015) stated that more interconnections can make the financial system more fragile due to increased shock propagation when shocks are either large or coincidental. These findings are supported by Markose et al. (2012), who referred to institutions that are 'too interconnected' as 'super-spreaders' of shocks. Minoiu and Reyes (2013) analyzed the global banking network using 184 countries and reported that connectivity in the banking network tends to increase particularly when the market is under stress. This aligns with the findings of Glasserman and Young (2015), which asserted that interconnectedness among different markets were key contributors to the GFC of 2007-2009. Yellen (2013) regarded interconnectedness as a financial stability concern after the occurrence of the global crisis while Sun and Chan-Lau (2017) argued that interconnectedness was the source of systemic risk.

The third strand of literature shows that specific institutions or markets play a key role in spreading shocks in the network. For instance, by investigating the patterns of international trade and financial integration, Schiavo et al. (2010) demonstrated a cause of the global crisis was shocks spreading from advanced economies to other markets, leading to network-wide distress. Kubelec and Sá (2012) found the US and UK to be the key players in the global financial network, with high interconnections compared to the rest of the world.

\subsection{Spatial econometric concept}

Introduction of spatial econometric techniques into financial application can be useful in modeling spillovers. The spatial econometric technique has been used recently in finance. For example, Eder and Keiler (2015) used it to model contagion risk among financial institutions; Fernandez (2011) employed it to measure risk premium propagation among firms; Asgharian et al. (2013) used it to investigate stock market co-movements while Catania and Billé (2017) applied it to advancements in score-driven models typically used in time series econometrics.

Spatial dependence parameter (network intensity parameter) captures the strength of the spatial dependent units; thus, it is a key component in investigating the structure of the spatial autoregressive process. Network intensity parameter falls within the range of 0 and 1, where 0 (1) is the minimum (maximum) estimate. A robustyet-fragile financial system is associated with high (greater than 0 and approaching 1) network intensity. Financial systems benefit from high network intensity through risk-sharing and diversification. Conversely, increasing intensity beyond certain limits will increase the rate at which shocks propagate, leading to financial instability (Eder \& Keiler, 2015). As a consequence, the financial system benefits from relative high network intensity (especially when there is no shock hitting the system), which 
allows for effective absorption of shocks rather than their amplification them to the entire system (Affinito \& Pozzolo, 2017). Restricting network intensity parameters may improve stability leading to a more robust financial system (Gofman, 2017).

In addition, since estimation of network intensity depends on the connection matrix, the structure of the connection matrix will have an impact on the estimation of network intensity. Let $d \in[\underline{d}, \bar{d}]$ be the degree of network connectivity, where $\underline{d}$ and $\bar{d}$ are the minimum and maximum degree of connectivity respectively; then, a robust-yet-fragile network is associated with degree of connectivity close to $\bar{d}$. The network is robust in the sense that the risk-sharing and diversification are higher in the absence of large shocks and fragile when large shocks hit the network. High connectivity with shocks hitting the financial system imply more shocks being propagated in the network causing a fragile financial system (Glasserman \& Young, 2015).

Consider a full or complete network with equivalent row-normalized weighted connection matrix, an example represented as:

$$
W=\left(\begin{array}{ccccc}
0 & 0.25 & 0.25 & 0.25 & 0.25 \\
0.25 & 0 & 0.25 & 0.25 & 0.25 \\
0.00 & 0.50 & 0 & 0.00 & 0.50 \\
0.25 & 0.25 & 0.25 & 0 & 0.25 \\
0.25 & 0.25 & 0.25 & 0.25 & 0
\end{array}\right)
$$

A shock hitting the above network will be proportionally shared among the nodes in the network depending on the weights of the edges. The shock will either be equally shared or proportionally shared across the entire system depending on the size of the shock. Thus, a robust network exists when shocks are equally distributed to all institutions since the network is more resilient to small shocks (Hüser, 2015). Conversely, when weights are beyond a certain threshold, the risk-sharing effect is endangered by larger shocks being amplified in the financial system rather than being contained. This implies that shocks will affect nodes that are strongly interconnected.

Generally, financial institutions benefit from high connectivity in the absence of shocks, while high connectivity can lead to financial instability when large shocks hit the system. This argument is supported by various studies. For example, Haldane (2009) asserted that high connectivity in the financial system leads to greater risk-sharing and diversification; above certain connectivity thresholds, it will propagate shocks to the entire system. In addition, Vitali et al. (2016) argued that high connectivity beyond certain threshold leads not only to large systemic events, but also to more frequent occurrence of distress events. Acemoglu et al. (2015) also found that highly connected institutions are more resilient to small shocks that pose a high chance of contagion in the presence of large shocks. This is also supported by Silva et al. (2016), who identified a high potential for a default to be triggered, especially in a dense interconnected network since risk-sharing effects vanish when large shocks hit this network. Schiavo et al. (2010) suggested that the structure of the connection determines how the financial system responds to shocks. 
Estimates of network intensity are dependent on the interaction of the endogenous spatial lag ( $W y)$; thus, increasing interactions (a denser weighting matrix) leads to greater amplification of shocks rather than sharing shocks across these networks. This is supported by various studies. For example, using European CDS spread data, Blasques et al. (2016) showed that high time-varying spatial coefficients are associated with credit riskiness, which leads to fragility and potential collapse of financial system. Battiston et al. (2012) found that financial systems can be more resilient when the financial accelerator is low; when it is at a maximum, adverse effects are inflicted via spreading shocks. This suggests that when shocks hit the financial system, a high network intensity estimate signifies a higher probability that the financial system will be fragile (Vitali et al., 2016).

\subsection{Motivation and hypotheses development}

Financial integration is a process through which either financial markets, countries or regions become interconnected in different ways. This process includes crossborder lending and borrowing and is an important phenomenon in financial markets. Increasing integration is often associated with a more complex financial sector. Financial integration is beneficial to markets in terms of efficient capital allocation, higher investment and growth opportunities and risk-sharing. Risk-sharing improves the resilience of the global financial system (González-Páramo, 2010). ${ }^{3}$

Financial integration also serves to spread shocks to the entire financial system. According to Schiavo et al. (2010), it is through integration that advanced economies become more interconnected with other markets, thereby spreading shocks to these markets. This leads to global distress and increased cross-border exposure threatening financial system stability. Hüser (2015) showed that an increase in the integration of the interbank network poses an increased risk of contagion, and as a consequence increases systemic risk. Asgharian et al. (2013) argued that cause of the Asian crisis was trade integration (measured by cross-border flows of imports and exports) between Asian countries, especially those emanating from Thailand and spreading rapidly to its neighbors (Indonesia, Malaysia and even Korea). In this context, we consider financial integration a contributory factor to increased network intensity. As countries engage in cross-border activities, financial integration expands potentially making financial markets more volatile.

Based on these motivation and related literature, we outline four hypotheses:

Hypothesis 1: Network intensity increases during periods of stress. This hypothesis tests whether network intensity estimate changes over time. It will determine whether it tends to increase or decrease when the market is under stress. We would expect network intensity to increase when shocks hit the network.

\footnotetext{
3 See González-Páramo (2010) for more details on the benefit of financial integration in the global financial system.
} 
Hypothesis 2: Degree of connectivity affects estimation of network intensity. This aims to investigate whether greater interconnectedness among different markets influences estimation of network intensity parameter. This will provide an insight into how the connection matrix makes the financial network robust-yet-fragile.

Hypothesis 3: Financial integration affects the estimation of network intensity. This tests whether financial integration can explain why network intensity increases or decreases during different periods. With increasing cross-border activities, markets have become more integrated forming a possible channel through which shocks can spread in financial systems.

Hypothesis 4: Advanced economies have a greater impact in spreading shocks. This tests whether developed economies have a greater impact in the estimation of network intensity. This test is in line with Schiavo et al. (2010), who found that advanced economies were the key spreaders of shocks during the GFC.

\section{Financial network and exposure to common factors}

We now consider the impact of exposure to common factors in financial networks. This involves examination of how the structural model (which incorporates both systematic and idiosyncratic shocks) behaves in the presence of network exposure.

The starting point focus on the structural model, capturing exposures to common factors as considered in Billio et al. (2015). According to Sharpe (1964) and Lintner (1965), the traditional capital asset pricing model (CAPM) is given by:

$$
r_{i t}-r_{f t}=\alpha_{i t}+\beta_{i t}\left(r_{m t}-r_{f t}\right)+\varepsilon_{i t}
$$

where $r_{i t}$ is the return on stock $i$ at time $t, r_{m t}$ is the market return at time $t, r_{f t}$ is the risk-free rate and $\varepsilon_{i t}$ is a vector capturing the idiosyncratic shocks of stock $i$ at time $t$. $\alpha_{i t}$ and $\beta_{i t}$ are the parameters of the model.

The traditional CAPM model can be extended to the Fama-French three-factor linear model. Considering the pricing perspective, the Fama-French three-factor for a set of risk asset returns, $r_{i t}$ at time $t$ is given by:

$$
r_{i t}-r_{f t}=\alpha_{i t}+\beta_{i t}\left(r_{m t}-r_{f t}\right)+h_{i t} H M L_{i t}+s_{i t} S M B_{i t}+\varepsilon_{i t}
$$

where $H M L$ is the book-to-market factor of stock $i$ at time $t, S M B_{i t}$ is the size factor of stock $i$ at time $t$. $h_{i t}$ and $s_{i t}$ are additional parameters of the model; $\varepsilon_{i t}$ is a vector capturing the idiosyncratic shocks of stock $i$ at time $t$.

The main focus of this approach is on both network exposures (endogenous) and exposures to common factors (structural exposure, which is exogenous). Equation (2) can be rewritten in a structural form as:

$$
\begin{gathered}
S\left(r_{i t}-\mathbb{E}\left[r_{i t}\right]\right)=\beta_{M} r_{i t}^{M}+\beta_{H M L} r_{i t}^{H M L}+\beta_{S M B} r_{i t}^{S M B}+\eta_{i t} \\
r_{i t}-\mathbb{E}\left[r_{i t}\right]=S^{-1}\left(\beta_{M} r_{i t}^{M}+\beta_{H M L} r_{i t}^{H M L}+\beta_{S M B} r_{i t}^{S M B}+\eta_{i t}\right)
\end{gathered}
$$


The spatial matrix $S$ in Eq. (4) captures the contemporaneous relations associated with interconnections between different assets, while $\eta_{t}$ is the structural idiosyncratic risk at time $t$.

Our aim is to construct a structural model that contains contemporaneous relationships driven by links across assets, and systematic and idiosyncratic shocks. Thus, the spatial matrix $S$ can be parametrized as $S=I_{n}-\rho W$, where $I_{n}$ is $n \times n$ identity matrix, $|\rho|<1$ is the spatial dependence parameter (network intensity parameter) indicating the strength of the network exposure. It monitors the network impact while $W$ represents relationships across assets. ${ }^{4}$

Equation (4) into a spatial autoregressive framework (SAR) as:

$$
\begin{gathered}
\left(I_{n}-\rho W\right)\left(r_{i t}-\mathbb{E}\left[r_{t}\right]\right)=\beta_{M} r_{i t}^{M}+\beta_{H M L} r_{i t}^{H M L}+\beta_{S M B} r_{i t}^{S M B}+\eta_{i t} \\
r_{i t}-\mathbb{E}\left[r_{i t}\right]=\left(I_{n}-\rho W\right)^{-1}\left(\beta_{M} r_{i t}^{M}+\beta_{H M L} r_{i t}^{H M L}+\beta_{S M B} r_{i t}^{S M B}+\eta_{i t}\right)
\end{gathered}
$$

If we let $\beta_{M} r_{i t}^{M}+\beta_{H M L} r_{i t}^{H M L}+\beta_{S M B} r_{i t}^{S M B}=Z$, using a geometric series expansion to the first degree, ${ }^{5}$ the above model can be represented as:

$$
r_{i t}-\mathbb{E}\left[r_{i t}\right]=\underbrace{Z}_{\mathrm{i}}+\underbrace{\eta_{i t}}_{\mathrm{ii}}+\underbrace{\sum_{j=1}^{\infty} \rho^{j} W^{j} Z}_{\mathrm{iii}}+\underbrace{\sum_{j=1}^{\infty} \rho^{j} W^{j} \eta_{i t}}_{\mathrm{iv}}
$$

where

i. structural exposure to common factors

ii. structural impact to idiosyncratic component

iii. network exposure to common factors

iv. network impact to idiosyncratic component

Equation (7) captures the impact of exposures (both structural and network exposures) of both systematic and idiosyncratic shocks. Therefore, we conclude that both idiosyncratic and systematic components are influenced by the presence of interconnections across assets/institutions.

\section{Dataset and effect of network exposure}

The empirical analysis of this paper uses different datasets. We use daily return constructed from daily equity market indices obtained from Thompson Reuter's Datastream. We also used the liability, market value and 90 days treasury bill (T-Bill)

\footnotetext{
${ }^{4}$ See Anselin (1988) for more details on spatial econometrics. For simplicity, we refer to $\rho$ as the network intensity parameter.

5 By geometric expansion, we have $\left(I_{n}-\rho W\right)^{-1}=I_{n}+\rho W+\rho^{2} W^{2}+\ldots$, where $\rho W$ represent the influence of neighbors on each unit while $\rho^{2} W^{2}$ second neighborhood influences each unit and so on.
} 
rates data. Other datasets that include foreign exchange (FX), interest rate (IR), S\&P 500 volatility index-US (VIX), Euro STOXX 50 volatility index-Europe (VSTOXX) and trade were also considered in the second part of the analysis.

We chose our sample of markets based on the availability of: (i) closing values, (ii) closing hours, and (iii) changes in closing prices, listed by region in Table 1. Our analysis of equity return spillovers is based on local currencies to avoid blurring the extent of market co-movements with fluctuations in the foreign exchange market (Mink, 2015).

The daily return $\left(r_{t}\right)$ for all markets are calculated as the log differences of the total daily equity market indices of a given economy at time $t$. This can be expressed as:

$$
r_{t}=\ln \left(P_{t} / P_{t-1}\right) \times 100
$$

where $r_{t}$ is the return at time $t, P_{t}$ is the closing stock price of a given financial institution at time $t, P_{t-1}$ is the lagged price and $\ln$ is the natural logarithm.

We study 42 stock markets in three categories: developed, emerging, and frontier. We extended the previous research that primarily focused on a few developed or emerging markets (e.g. the G7 [Canada, France, Germany, Italy, Japan, the UK and the US] stock markets investigated by Apostolakis and Papadopoulos (2014), the 10 developed and 11 emerging markets in Asia studied by Yarovaya et al. (2016), and Asian markets examined by Narayan et al. (2014) and did not consider all possible interconnectedness across different stock markets).

Table 2 presents the descriptive statistic of the daily returns for each market. The mean returns are positive for all economies with standard deviation ranging from 0.0096 to 0.0237 . The kurtosis results suggest that the daily return would be 'peaked' and have 'fat-tailed' distribution. Unit root tests revealed the usual characteristics of stationary returns in each series. The analysis was conducted using demeaned returns (as the mean is usually extremely close to 0 and, as we are focused on variance decompositions, this assumption is innocuous). Analysis of the complete network, consisting of 42 nodes, formed the initial benchmark for the study.

To construct our network, we used the data with its recorded local closing time date. The choice of time-zone treatment can have dramatic effects; no single choice is dominant due to the complications of wanting to test for two-way causality. Other researchers have used the dates as provided with the data (Wang et al., 2018), averaged data over consecutive days (Forbes \& Rigobon, 2002) or used time-matched data series (Kleimeier et al., 2008). Although the last of these is arguably the most appropriate, it is difficult to obtain these data for the markets examined here and to control for problems associated with out-of-local trading time liquidity effects (most markets have different price-impact effects during local and non-local trading). The averaging procedure used by Forbes and Rigobon (2002) introduced a moving average bias into the problem, and, with Granger-causality testing, created additional problems with the performance of the statistic. Further, it is debated whether the use of lagged or non-lagged samples introduces or reduces noise in the process. Sensitivity analysis to different choices of date-lagging produced important differences; the most pronounced of 
Table 1 List of country-specific stock indices and their corresponding Thomson Reuters Datastream codes

\begin{tabular}{|c|c|c|c|}
\hline Country code & Country name & Stock index & Datastream code \\
\hline \multicolumn{4}{|l|}{ European } \\
\hline AT & Austria & ATX-AUSTRIAN TRADED INDEX & ATXINDX \\
\hline $\mathrm{BE}$ & Belgium & BEL 20 & BGBEL20 \\
\hline $\mathrm{CZ}$ & Czech Republic & PRAGUE SE PX & CZPXIDX \\
\hline DK & Denmark & OMX COPENHAGEN (OMXC20) & DKKFXIN \\
\hline FI & Finland & OMX HELSINKI 25 (OMXH25) & HEX25IN \\
\hline FR & France & FRANCE CAC 40 & FRCAC40 \\
\hline $\mathrm{DE}$ & Germany & DAX 30 PERFORMANCE & DAXINDX \\
\hline GR & Greece & ATHEX COMPOSITE & GRAGENL \\
\hline $\mathrm{HU}$ & Hungary & BUDAPEST (BUX) & BUXINDX \\
\hline $\mathrm{IE}$ & Ireland & IRELAND SE OVERALL (ISEQ) & ISEQUIT \\
\hline IT & Italy & FTSE MIB INDEX & FTSEMIB \\
\hline NL & Netherlands & AMSTERDAM MIDKAP & AMSMKAP \\
\hline PL & Poland & WARSAW GENERAL INDEX 20 & POLWG20 \\
\hline PT & Portugal & PORTUGAL PSI-20 & POPSI20 \\
\hline ES & Spain & IBEX 35 & IBEX35I \\
\hline SE & Sweden & OMX STOCKHOLM 30 (OMXS30) & SWEDOMX \\
\hline $\mathrm{CH}$ & Switzerland & SWISS MARKET (SMI) & SWISSMI \\
\hline TR & Turkey & BIST NATIONAL 100 & TRKISTB \\
\hline UK & United Kingdom & FTSE ALL SHARE & FTALLSH \\
\hline \multicolumn{4}{|l|}{ Americas } \\
\hline CA & Canada & S\&P/TSX COMPOSITE & TTOCOMP \\
\hline US & United States & S\&P 500 COMPOSITE & S\&PCOMP \\
\hline AR & Argentina & ARGENTINA MERVAL & ARGMERV \\
\hline $\mathrm{BR}$ & Brazil & BRAZIL BOVESPA & BRBOVES \\
\hline CL & Chile & CHILE SANTIAGO SE GENERAL (IGPA) & IGPAGEN \\
\hline MX & Mexico & MEXICO IPC (BOLSA) & MXIPC35 \\
\hline \multicolumn{4}{|l|}{ Asia } \\
\hline AU & Australia & S\&P/ASX 200 & ASX200I \\
\hline $\mathrm{CN}$ & China & SHANGHAI SE COMPOSITE & CHSCOMP \\
\hline JP & Japan & NIKKEI 225 STOCK AVERAGE & JAPDOWA \\
\hline IN & India & S\&P BSE NATIONAL 200 & IBOM200 \\
\hline ID & Indonesia & IDX COMPOSITE & JAKCOMP \\
\hline $\mathrm{HK}$ & Hong Kong & HANG SENG & HNGKNGI \\
\hline MY & Malaysia & DJGL MALAYSIA DJTM MALAYSIA & DJMALYL \\
\hline $\mathrm{NZ}$ & New Zealand & $\mathrm{S} \& \mathrm{P} / \mathrm{NZX} 50$ & NZ50CAP \\
\hline PK & Pakistan & KARACHI SE 100 & PKSE100 \\
\hline $\mathrm{PH}$ & Philippines & PHILIPPINE SE I(PSEi) & PSECOMP \\
\hline SG & Singapore & STRAITS TIMES INDEX & SNGPORI \\
\hline $\mathrm{KR}$ & South Korea & KOREA SE KOSPI 200 & KOR200I \\
\hline LK & Sri Lanka & COLOMBO SE ALL SHARE & SRALLSH \\
\hline TW & Taiwan & TAIWAN SE WEIGHED TAIEX & TAIWGHT \\
\hline
\end{tabular}


Table 1 (continued)

\begin{tabular}{llll}
\hline Country code & Country name & Stock index & Datastream code \\
\hline TH & Thailand & BANGKOK S.E.T. & BNGKSET \\
Africa & & & \\
EG & Egypt & MSCI EGYPT & MSEGYTL \\
ZA & South Africa & FTSE/JSE ALL SHARE & JSEOVER \\
\hline
\end{tabular}

these is that when the US data are lagged, there is virtually no evidence of transmission from the US to Asia, which seems at odds with our understanding of international financial markets and the transmission of shocks. Consequently, this chapter uses the convention of actual day dating in its analysis.

We first examine the evolution of the unweighted and weighted networks over the sample period and augmented this analysis with scenarios based on alternative clustering of markets, as per the Asian Development Bank member countries and the role of regional groupings, including the Association of Southeast Asian Nations (ASEAN) with other regions across the globe.

The sample period considered is January 1999-December 2017 because our focus is to observe the dynamics of the network exposure in the twenty-first century. By taking advantage of the long horizon with a large number of observations (4956), we subdivided the sample into four phases, as represented in Table 3: Phase 1 is the pre-crisis (1 January 1999-14 September 2008) period, Phase 2 is the GFC (15 September 2008-31 March 2010) period, Phase 3 is the European debt crisis (EDC) (1 October 2010-21 November 2013) and phase three is the most recent period (22 November 2014-29 December 2017). We followed Dungey et al. (2015) and Dungey and Renault (2018) when choosing these dates.

We use the BIS database to obtain liabilities data to construct the weighting matrix. The BIS bilateral locational banking statistics provided a comprehensive cross-border data set of international banking transactions. This included aggregate international cross-border claims and liabilities of a set of both reporting and non-reporting countries. We use cross-border liabilities of reporting countries, measured on a quarterly basis from 1999Q1-2017Q4 to construct the connection matrix. The weighting matrix is obtained using the combined Granger causality and DY approach (see Chowdhury et al., 2019). Each country is represented by direct liability towards all the other countries in all financial sectors (central banks, banks, non-bank financial institutions and non-financial sectors). We consider 42 (mature and emerging markets) countries in our sample (see Table 4), for which the data were complete and reliable. We also use different specifications of the connection matrix in our empirical analysis. Particularly, we randomly generated sparse (fewer interconnections) and denser (more interconnections) matrices for the markets in our sample. $^{6}$

\footnotetext{
${ }^{6}$ Sparse connection matrix will be used to investigate the effect of network exposures with decreased interconnectedness while denser connection matrix will be used to investigate the effect of network exposure with increased interconnectedness.
} 
Table 2 Descriptive statistics of daily return for each market

\begin{tabular}{|c|c|c|c|c|c|c|c|c|}
\hline Country & Mean & Min & Max & Std. dev & Kurtosis & Skewness & ADF test & No. obs. \\
\hline AT & 0.0002 & -0.0974 & 0.1277 & 0.0135 & 10.7384 & -0.2140 & $-71.1573^{* *}$ & 5739 \\
\hline $\mathrm{BE}$ & 0.0003 & -0.0829 & 0.1087 & 0.0111 & 9.9523 & 0.0112 & $-70.3872^{* *}$ & 5739 \\
\hline $\mathrm{CZ}$ & 0.0002 & -0.1494 & 0.1316 & 0.0132 & 14.8753 & -0.1718 & $-69.4570^{* *}$ & 5739 \\
\hline DK & 0.0004 & -0.1091 & 0.0986 & 0.0113 & 9.7303 & -0.2713 & $-71.1096^{* *}$ & 5739 \\
\hline FI & 0.0004 & -0.0897 & 0.0973 & 0.0152 & 6.5627 & -0.1113 & $-73.8211^{* *}$ & 5739 \\
\hline FR & 0.0003 & -0.0904 & 0.1118 & 0.0143 & 7.8396 & 0.0829 & $-77.0792^{* *}$ & 5739 \\
\hline $\mathrm{DE}$ & 0.0004 & -0.0849 & 0.1140 & 0.0147 & 7.5954 & -0.0077 & $-76.5194 * *$ & 5739 \\
\hline GR & 0.0000 & -0.1902 & 0.1327 & 0.0189 & 10.6342 & -0.1824 & $-68.5693^{* *}$ & 5739 \\
\hline $\mathrm{HU}$ & 0.0007 & -0.1650 & 0.1459 & 0.0166 & 13.5187 & -0.2345 & $-71.7532^{* *}$ & 5739 \\
\hline IE & 0.0003 & -0.1303 & 0.1022 & 0.0129 & 11.3909 & -0.5090 & $-71.4974 * *$ & 5739 \\
\hline IT & 0.0001 & -0.1272 & 0.1161 & 0.0149 & 7.8602 & -0.0388 & $-76.8145^{* *}$ & 5739 \\
\hline NL & 0.0003 & -0.0950 & 0.0830 & 0.0124 & 7.4651 & -0.4448 & $-68.6160^{* *}$ & 5739 \\
\hline PL & 0.0003 & -0.1320 & 0.1469 & 0.0168 & 7.4476 & 0.0083 & $-74.4086^{* *}$ & 5739 \\
\hline PT & 0.0001 & -0.0986 & 0.1073 & 0.0118 & 9.9042 & -0.2103 & $-68.3531 * *$ & 5739 \\
\hline ES & 0.0003 & -0.1235 & 0.1443 & 0.0146 & 8.9329 & 0.0124 & $-74.0971 * *$ & 5739 \\
\hline SE & 0.0004 & -0.0842 & 0.1165 & 0.0147 & 7.2704 & 0.1721 & $-77.0466^{* *}$ & 5739 \\
\hline $\mathrm{CH}$ & 0.0003 & -0.0867 & 0.1139 & 0.0118 & 9.5391 & -0.0438 & $-73.2515^{* *}$ & 5739 \\
\hline TR & 0.0013 & -0.1768 & 0.1856 & 0.0237 & 9.3668 & 0.3075 & $-73.9692^{* *}$ & 5739 \\
\hline GB & 0.0002 & -0.0834 & 0.0921 & 0.0108 & 9.3767 & -0.0988 & $-75.9863^{* *}$ & 5739 \\
\hline $\mathrm{AR}$ & 0.0006 & -0.1684 & 0.1775 & 0.0224 & 9.3782 & 0.1776 & $-70.0926^{* *}$ & 5739 \\
\hline BR & 0.0006 & -0.1312 & 0.2796 & 0.0188 & 18.5465 & 0.7545 & $-72.1713^{* *}$ & 5739 \\
\hline CL & 0.0002 & -0.0710 & 0.1475 & 0.0106 & 14.8593 & 0.4589 & $-63.2493^{* *}$ & 5739 \\
\hline MX & 0.0006 & -0.1334 & 0.1292 & 0.0146 & 10.6563 & 0.2751 & $-68.8651^{* *}$ & 5739 \\
\hline $\mathrm{CA}$ & 0.0003 & -0.0932 & 0.0982 & 0.0105 & 12.5107 & -0.5306 & $-74.9890^{* *}$ & 5739 \\
\hline US & 0.0003 & -0.0903 & 0.1158 & 0.0117 & 11.6484 & -0.0660 & $-80.9848^{* *}$ & 5739 \\
\hline $\mathrm{AU}$ & 0.0002 & -0.0834 & 0.0589 & 0.0096 & 8.5885 & -0.3593 & $-77.1427^{* *}$ & 5739 \\
\hline $\mathrm{CN}$ & 0.0004 & -0.1639 & 0.3099 & 0.0175 & 25.8061 & 0.7424 & $-73.9442 * *$ & 5739 \\
\hline IN & 0.0005 & -0.1187 & 0.1631 & 0.0149 & 10.0010 & -0.1242 & $-69.1956^{* *}$ & 5739 \\
\hline ID & 0.0005 & -0.1195 & 0.1403 & 0.0151 & 11.8284 & 0.0327 & $-65.6407 * *$ & 5739 \\
\hline JP & 0.0001 & -0.1141 & 0.1415 & 0.0149 & 8.7971 & -0.1237 & $-78.7296^{* *}$ & 5739 \\
\hline HK & 0.0003 & -0.1370 & 0.1882 & 0.0160 & 14.7057 & 0.3911 & $-76.4475^{* *}$ & 5739 \\
\hline MY & 0.0002 & -0.2071 & 0.2344 & 0.0127 & 65.9316 & 1.8058 & $-69.8174 * *$ & 5739 \\
\hline $\mathrm{NZ}$ & 0.0001 & -0.1507 & 0.1179 & 0.0104 & 15.9717 & -0.3705 & $-76.3666^{* *}$ & 5739 \\
\hline PK & 0.0007 & -0.1238 & 0.1361 & 0.0147 & 9.9650 & -0.1841 & $-69.2419^{* *}$ & 5739 \\
\hline $\mathrm{PH}$ & 0.0002 & -0.1278 & 0.1769 & 0.0148 & 15.0100 & 0.5099 & $-66.7017 * *$ & 5739 \\
\hline SG & 0.0001 & -0.0936 & 0.1160 & 0.0126 & 9.9460 & 0.1695 & $-71.7193^{* *}$ & 5739 \\
\hline $\mathrm{KR}$ & 0.0003 & -0.1196 & 0.1572 & 0.0180 & 9.3491 & 0.2213 & $-72.4785^{* *}$ & 5739 \\
\hline LK & 0.0004 & -0.1297 & 0.2007 & 0.0105 & 42.2018 & 0.9596 & $-61.2101 * *$ & 5739 \\
\hline $\mathrm{TH}$ & 0.0001 & -0.1484 & 0.1202 & 0.0152 & 10.9150 & 0.2835 & $-70.1885^{* *}$ & 5739 \\
\hline $\mathrm{TW}$ & 0.0001 & -0.0980 & 0.0961 & 0.0149 & 6.0186 & 0.0605 & $-74.3705^{* *}$ & 5739 \\
\hline
\end{tabular}


Table 2 (continued)

\begin{tabular}{lllllllll}
\hline Country & Mean & Min & Max & Std. dev & Kurtosis & Skewness & ADF test & No. obs. \\
\hline ZA & 0.0005 & -0.1278 & 0.0816 & 0.0118 & 9.5149 & -0.4721 & $-69.8633^{* *}$ & 5739 \\
EG & 0.0007 & -0.1552 & 0.1385 & 0.0162 & 10.0429 & 0.0050 & $-68.2147 * *$ & 5739 \\
\hline
\end{tabular}

The sample period is January 1995-December 2016. The augmented Dickey-Fuller (ADF) statistic tests for unit root

** Statistical significance at a $5 \%$ level

Table 3 Phases of the sample

\begin{tabular}{llll}
\hline Phase & Period & Representing & $\begin{array}{l}\text { Number of } \\
\text { observa- } \\
\text { tions }\end{array}$ \\
\hline All phases & $01.01 .1999-29.12 .2017$ & Entire period & 4956 \\
Phase 1 & $01.01 .1999-14.09 .2008$ & Pre-crisis & 2531 \\
Phase 2 & $15.09 .2008-31.03 .2010$ & Global financial crisis & 403 \\
Phase 3 & $01.04 .2010-21.11 .2013$ & European debt crisis & 951 \\
Phase 4 & $22.11 .2013-29.12 .2017$ & Recent period & 1071 \\
\hline
\end{tabular}

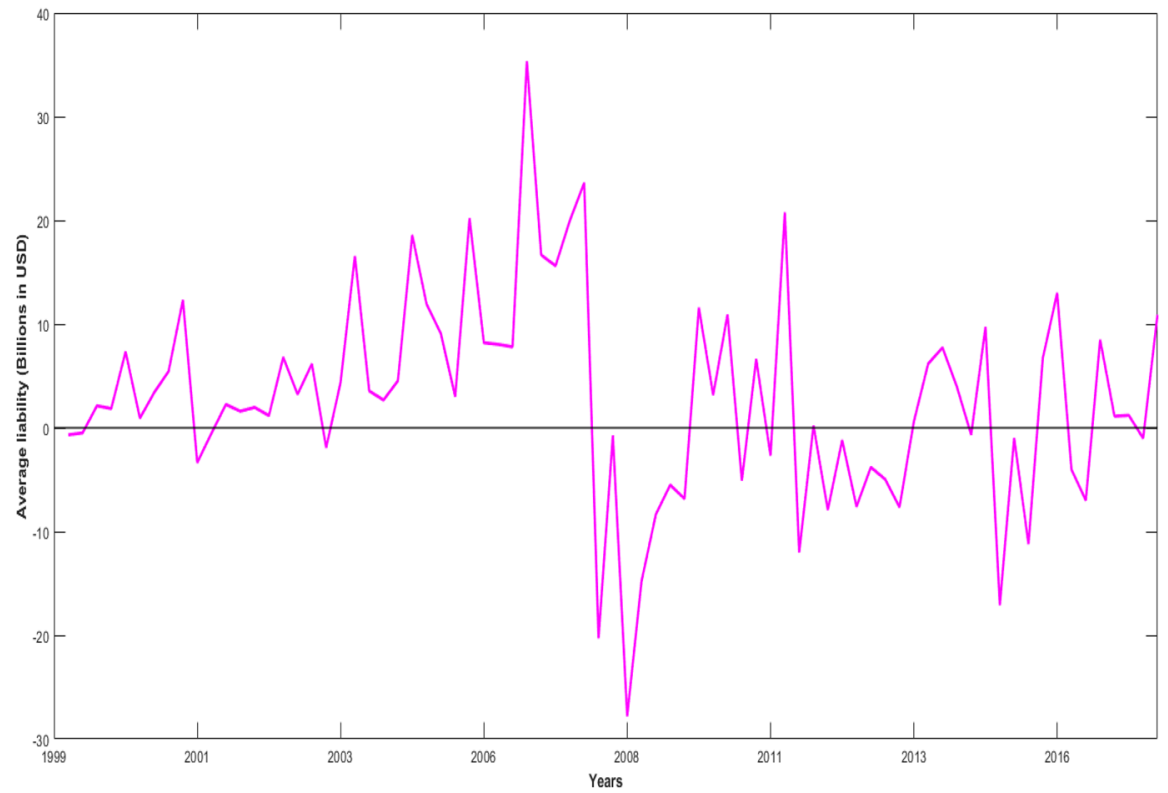

Fig. 1 Average liability for the countries included in this study: 1999Q1-2017Q4.

The source of the data is BIS database with our own plotting 
Table 4 Structural betas for countries in our sample

\begin{tabular}{|c|c|c|c|c|c|}
\hline Country & All phases & Phase 1 & Phase 2 & Phase 3 & Phase 4 \\
\hline Austria & 0.9090 & 0.8274 & 0.9694 & 1.0169 & 0.9924 \\
\hline Belgium & 0.0422 & 0.0134 & 0.8190 & 0.9975 & 0.9809 \\
\hline Czech Republic & 0.5767 & 0.5701 & 0.8952 & 0.2423 & 0.3125 \\
\hline Denmark & 0.0271 & 0.0145 & 0.9037 & 0.1605 & 0.5133 \\
\hline Finland & 0.5594 & 0.5234 & 0.9620 & 0.5400 & 0.2193 \\
\hline France & 0.0352 & 0.0676 & 0.9956 & 1.0077 & 0.9762 \\
\hline Germany & 0.8195 & 0.5882 & 0.9779 & 1.0063 & 0.9054 \\
\hline Greece & 0.0033 & 0.0032 & 0.0024 & 0.0570 & 0.0083 \\
\hline Hungary & 0.6966 & 0.6444 & 0.8784 & 0.7639 & 0.3745 \\
\hline Ireland & 0.3212 & 0.5090 & 0.0875 & 0.7248 & 0.9697 \\
\hline Italy & 0.1926 & 0.0663 & 0.9905 & 0.9991 & 0.9333 \\
\hline Netherlands & 0.8997 & 0.9320 & 0.8402 & 0.8932 & 0.9464 \\
\hline Norway & 0.8838 & 0.7685 & 0.9929 & 0.9766 & 0.8878 \\
\hline Poland & 0.0510 & 0.0316 & 0.9387 & 0.9882 & 0.9883 \\
\hline Portugal & 0.9515 & 0.8766 & 0.9958 & 0.9775 & 0.9806 \\
\hline Romania & 0.3757 & 0.3440 & 1.0007 & 0.9377 & 0.9911 \\
\hline Spain & 0.9295 & 0.8406 & 0.9951 & 0.9459 & 0.9805 \\
\hline Sweden & 0.1073 & 0.0308 & 0.9594 & 0.9977 & 0.9584 \\
\hline Switzerland & 0.1837 & 0.0420 & 0.9967 & 0.9978 & 0.9968 \\
\hline Turkey & 0.1006 & 0.1005 & 0.9740 & 0.9856 & 0.9654 \\
\hline United Kingdom & 0.4765 & 0.1825 & 0.9918 & 0.9810 & 0.9833 \\
\hline Argentina & 0.4963 & 0.2596 & 0.6725 & 0.9745 & 0.9940 \\
\hline Brazil & 0.7767 & 0.5681 & 0.9534 & 0.7994 & 0.8971 \\
\hline Chile & 0.9786 & 0.9900 & 1.0264 & 0.9822 & 0.8356 \\
\hline Mexico & 0.7463 & 0.7059 & 0.9603 & 0.7001 & 0.9993 \\
\hline Canada & 0.8965 & 0.9078 & 0.6805 & 0.9878 & 0.9823 \\
\hline United States & 0.2102 & 0.0383 & 0.9776 & 1.0006 & 0.9968 \\
\hline Australia & 0.4424 & 0.0911 & 0.8300 & 0.9899 & 0.9881 \\
\hline China & 0.0302 & 0.0040 & 0.8010 & 1.0001 & 0.9122 \\
\hline India & 0.7825 & 0.6903 & 0.9681 & 0.9860 & 1.0012 \\
\hline Indonesia & 0.8583 & 0.8606 & 0.7730 & 0.9007 & 0.8730 \\
\hline Japan & 0.0373 & 0.0076 & 0.8250 & 0.8125 & 0.9451 \\
\hline Hong Kong & 0.0195 & 0.0167 & 0.9617 & 0.3539 & 0.8560 \\
\hline Malaysia & 0.8413 & 0.8380 & 0.7939 & 0.9454 & 0.9828 \\
\hline New Zealand & 0.0448 & 0.0055 & 0.9888 & 0.9819 & 0.9933 \\
\hline Pakistan & 0.0033 & 0.0025 & 0.1978 & 0.8878 & 0.9124 \\
\hline Philippines & 0.6169 & 0.7677 & 0.0608 & 0.9821 & 0.9436 \\
\hline Singapore & 0.9806 & 0.9819 & 0.8075 & 0.8190 & 0.8837 \\
\hline South Korea & 0.0004 & 0.0002 & 0.7882 & 0.7543 & 0.7782 \\
\hline Sri Lanka & 0.8996 & -0.0014 & -0.0256 & 0.9792 & 0.9869 \\
\hline Thailand & 0.2956 & 0.2913 & 0.9771 & 0.1056 & 0.9502 \\
\hline Taiwan & 0.2038 & 0.1772 & 0.5884 & 0.8109 & 0.6233 \\
\hline South Africa & 0.9806 & 0.9791 & 0.9834 & 0.9785 & 0.9839 \\
\hline Egypt & 0.8001 & 0.7772 & 0.2363 & 0.9202 & 0.9857 \\
\hline Israel & 0.0816 & 0.0744 & 0.9789 & 1.0065 & 0.9684 \\
\hline
\end{tabular}

The period covered in the sample is 1 January 1999-31 December 2017. All coefficients are at a 5\% level of significance 
Figure 1 displays the average cross-border liability flow, measured in US billion dollars, for the countries in our sample. Liability defined as what a country or company owes to others (including loans, bonds and other debts), plays a significant role in propagating shocks in the financial system. Having unsecured lending and borrowing could increase cross-border liability within the financial system. There was a change in the average liability between the entire period of our sample. As shown in Fig. 1, the average liability drastically changed during crises, implying that on average, countries in our sample paid more than required by a liability. This may be a contributory factor to the collapse of the financial system, because the failure of these countries to pay liabilities could lead to defaults for their counter-parties. Therefore, liability within countries serves as a major contributory factor to crises. The higher the liability, the greater the chance of system exposure to distress. These findings concur with those of Gai and Kapadia (2010), who found that liability from defaulting banks led to the spread of contagion, which in turn increased the vulnerability of interconnected institutions.

\subsection{Effect of financial network to common factor model}

This subsection investigates whether network exposure affects common factors. This enables greater understanding of the importance of financial networks in both spreading and absorbing financial shocks in the system. Our investigation focuses on the individual countries in our sample. Following Billio et al. (2015), we estimated both systematic and idiosyncratic components in the structural model. Our analysis relied on estimating these parameters because the Fama-French factors available in Kenneth French's data library were limited to few countries. Since the idiosyncratic component is unobservable and model-dependent, we used indirect estimation proposed by Campbell et al. (2001) to estimate it.

\subsubsection{Estimating beta and idiosyncratic volatilities}

To estimate idiosyncratic volatility for an individual stock in our sample, we assumed the return of each country $i$ to be driven by a common factor and countryspecific shock $\varepsilon_{i t}$. To be precise, we followed Sharpe (1964) and Lintner (1965), who assumed a single factor return generating process and estimated the market model using Eq. (1).

In this analysis, we computed the excess returns of individual countries as the log return on the global market index $\left(r_{m t}\right)$ minus absolute change of 90 days' T-Bill rates $\left(r_{f t}\right)$, which we considered the risk-free rate. The 90 days' T-Bill rates and market value data were obtained from Thompson Reuter's Datastream for January 1999-December 2017.

The return on the global market index $\left(r_{m t}\right)$ was computed as the value of weighted excess return of each country over the 90 days T-Bill rates $r_{f t}$ of each country: 


$$
r_{m t}=\sum_{i=1}^{n} \omega_{i t} * r_{i t}
$$

where $\omega_{i t}$ is the ratio of country's $i$ market value to the total market value of the entire market $m$ in time $t$ and $n$ is the total number of countries.

The beta and residual estimates for each market were obtained by running the regression for each market index in the sample using Eq. (1).

Following Bali and Cakici (2008), we estimated country-specific idiosyncratic volatility as the standard deviation of the residuals of each individual country given by:

$$
I V O L_{i t}=\sqrt{\operatorname{var}\left(\varepsilon_{i t}\right)}
$$

\subsubsection{Effect of financial network on betas}

The beta estimate for each country was estimated by running separate regressions. Table 4 displays the structural betas for individual countries in our sample. We estimated betas using Eq. (1) for all phases categorized in Table 3. Our results clearly show that beta coefficients are different in all phases. In most countries, the structural betas were lower in the pre-crisis period, while increased in the GFC with the exception of some emerging markets (Indonesia, Malaysia, Philippines, Singapore, Sri Lanka and Egypt) in which estimates decreased during the global financial crisis period. The structural betas remain high in Phase 3, associated with the European debt crisis. Country-specific betas changed with the introduction of many factors. For instance, using Fama-French three-factor model might result in different estimates. Since our focus was the effect of network exposure on structural betas, we did not focus on discussing each country's specific betas.

Using beta coefficients obtained from the regression model, we investigated how they changed with the increase in network exposure. First, we examined the effect of the connection matrix $(W)$ on the structural beta. Figure 2a displays how the structural beta $\left(\bar{\beta}_{i}\right)$ changed with the interaction of the connection matrix, given by:

$$
\beta_{i}^{*}=\bar{\beta}_{i}+\sum_{i=1}^{n} W \bar{\beta}_{i}
$$

where $\beta_{i}^{*}$ is the new (augmented) beta obtained from the interaction with the connection matrix while $\bar{\beta}_{i}$ is the country-specific structural beta. The results show that the structural beta changes with the interaction with the connection matrix. The connection matrix is based on liability linkages obtained using the combined Granger causality and DY measure (Chowdhury et al., 2019). This suggests that the increased interconnection between various market participants leads to change in the structural beta of a given country. The results also revealed the role of the weighting matrix in spreading shocks in a financial system. For example, the connection matrix increased the values of structural betas by more than $50 \%$ for countries whose beta values were small. Countries with low betas included Greece, Philippines and Poland. The 

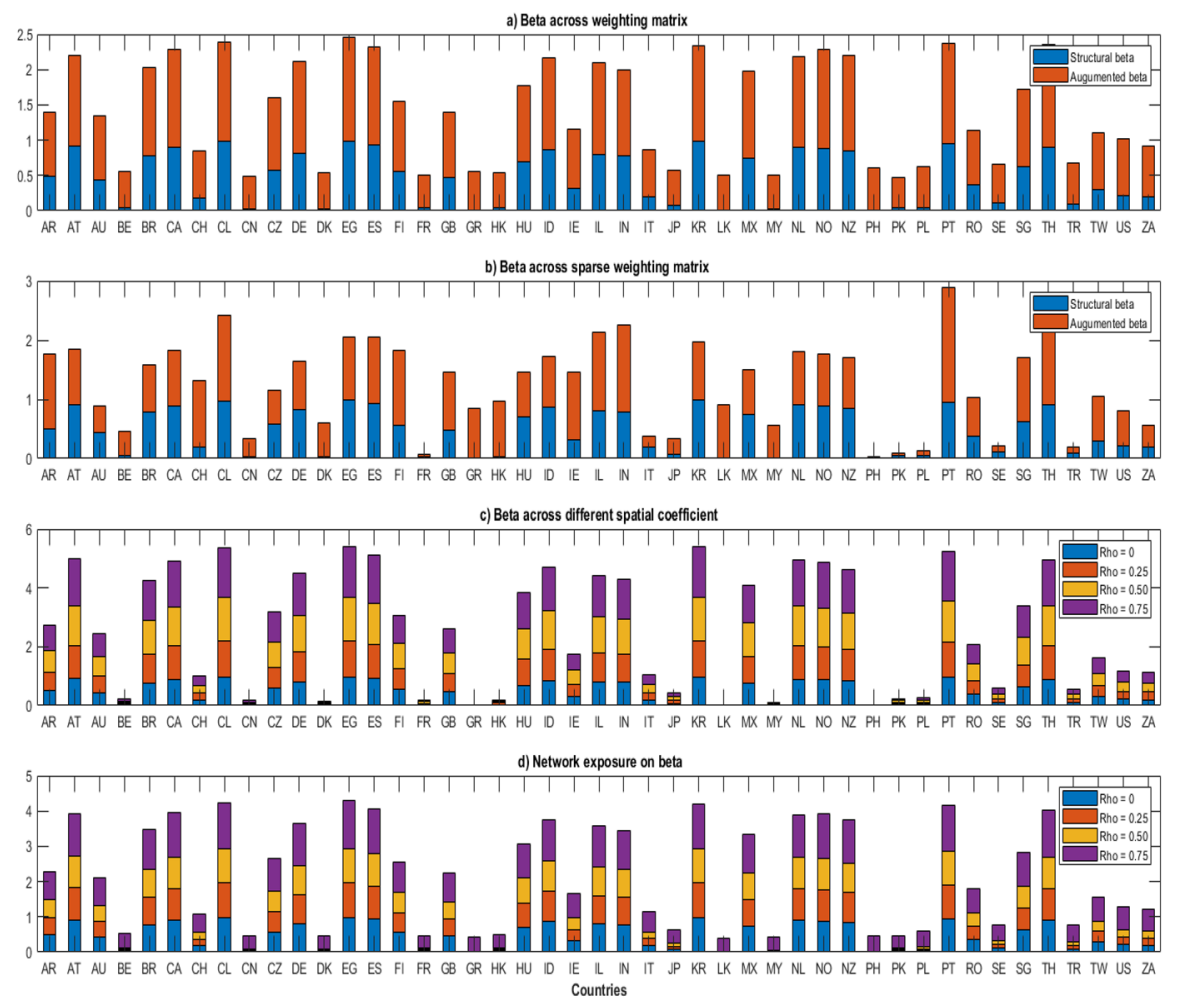

Fig. 2 Structural betas for all the phases under different scenarios. The figures exhibit how the structural beta for all phases changed under different scenarios. We used country' abbreviations from BIS. a Displays changes in betas with and without the presence of the connection matrix. This was obtained by multiplying the betas with the corresponding liability weighted matrix. b Shows how betas changed using sparse weighting matrix. c Shows how betas changed across different network intensity parameters. d Shows the effect of network exposure on betas. The period covered in the sample is 1 January 1999-31 December 2017

size of the augmented betas varied depending on the strength of the connections a country has with others. In Fig. 2a, we noted that beta values of countries (including Denmark, Greece, Sri Lanka, Malaysia and the Philippines) tend to be 0 but are greatly influenced by the weighting matrix. The beta values increased depending on the level of shock one country receives from others. These results depict the role of interconnections in spreading risk. This observation is consistent with Glasserman and Young (2016), who showed that countries with high connectivity tend to suffer more when shocks hit the financial system.

For countries (including Greece, Sri Lanka and the Philippines) with lower beta estimates due to stronger links with other countries, we observed that the structural beta was amplified. This implies that these countries are strongly affected by other countries, leading to amplification of shocks. 
It is important to understand whether using a different weighting matrix has a different impact on structural betas. Figure $2 b$ shows how betas changed using a sparse matrix. ${ }^{7}$ We randomly generated a sparse matrix. From the results, we noted that the contribution of the weighting matrix changed depending on the strength of connections between countries. This is depicted using orange bars in Figures $2 \mathrm{a}$ and $\mathrm{b}$. For example, the Philippines had stronger links in Fig. 2a, leading to greater change in exposure, while in Fig. 2b, it had weak links, leading to a smaller change in structural betas.

The impact of the different network intensity parameters on the structural betas can be estimated as:

$$
\beta_{i}^{* *}=\bar{\beta}_{i}+\sum_{i=1}^{n} \rho \bar{\beta}_{i}
$$

where $\beta_{i}^{* *}$ is the new beta obtained from the interaction with the different network intensity parameters.

Figure $2 \mathrm{c}$ shows how structural betas changed across the different network intensity parameters (we assumed network intensity parameters to take quartiles values [i.e. $0.25,0.5$ and 0.75$]$ ). It is clear from these that structural betas tend to increase across different network intensity parameters. This is an indicator that as the network intensity increases, the level of risk in the financial system also tends to increase. Unlike the connection matrix, whose effect is severe to all countries with stronger connections including countries whose beta values are small, the network intensity parameters have more influence on the countries whose beta values are large. Countries with small values of beta (Greece, Sri Lanka and the Philippines) are less affected by network intensity parameters. Conversely, countries with high beta estimates (e.g. South Korea) are more affected by larger network intensity parameters. This explains the role of network intensity parameters in spreading and reducing shocks. Our finding indicates that network intensity parameters have a greater impact in spreading risk than absorbing it.

Next, we investigated the effects of network exposure on structural betas. This involved combining the connection matrix and network intensity parameters. This is because both coefficients have a great impact on betas. We used the following equation to gauge the role of network exposure on structural betas:

$$
\beta_{i}^{* * *}=\bar{\beta}_{i}+\sum_{i=1}^{n} \rho W \bar{\beta}_{i}
$$

where $\beta_{i}^{* * *}$ is the new beta obtained from the interaction with the changing network exposure.

Figure $2 \mathrm{~d}$ shows how the structural betas change across the changing network exposure. These results show that both the weighting matrix and the network intensity parameters have effects on the structural beta.

\footnotetext{
7 We can define sparse matrix as a connection matrix with few interconnected institutions/assets.
} 


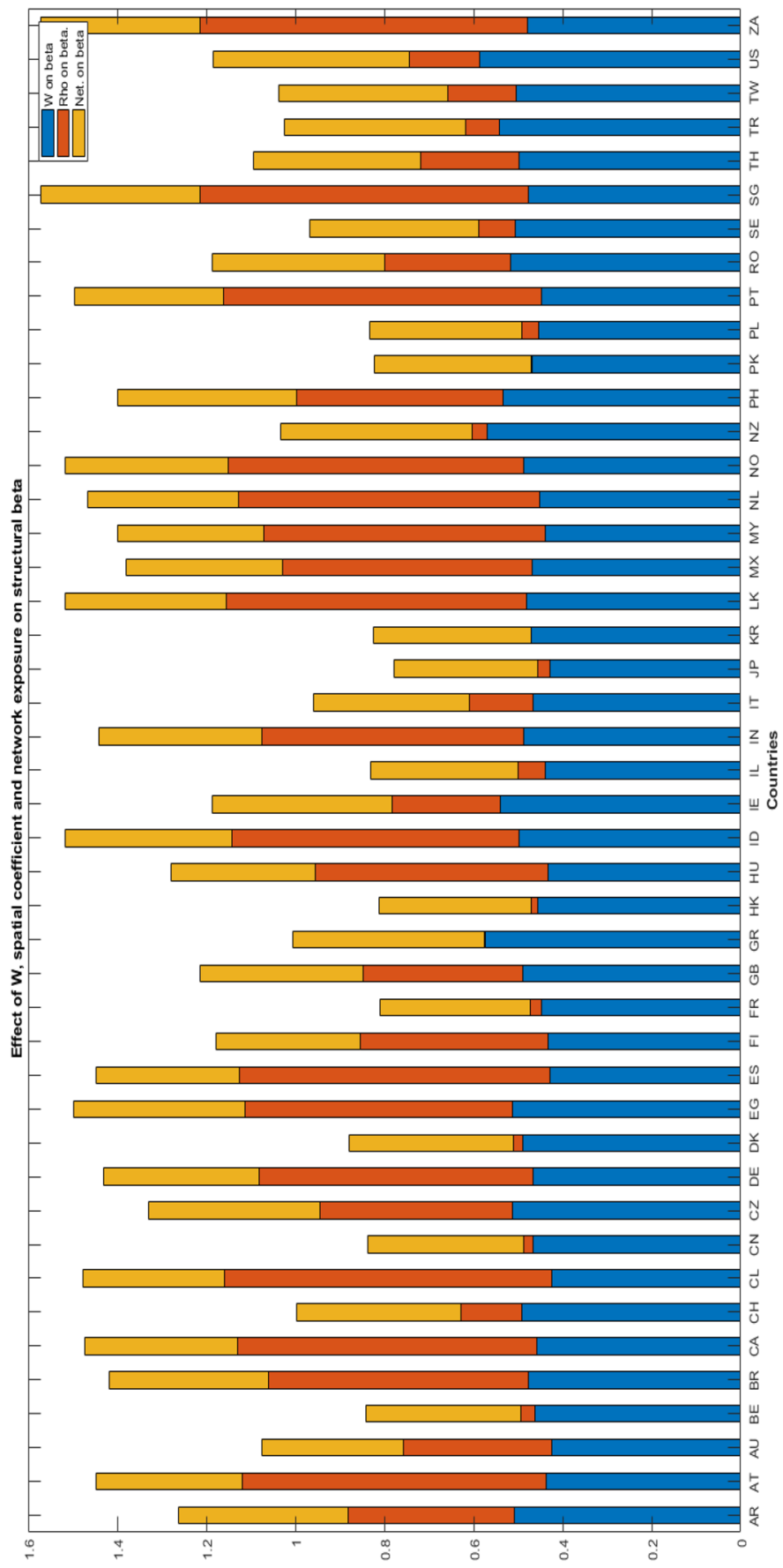


To obtain a clear insight into how structural beta changed, we calculated the percentage change in betas in $\beta_{i}^{*}, \beta_{i}^{* *}$ and $\beta_{i}^{* * *}$. Figure 3 summarizes the contribution of connection matrix, network intensity parameters and network exposure to structural betas. The height of the bar represents the percentage change of betas. These results revealed stronger connections between markets increase network exposure. This is consistent with Silva et al. (2016) who found that high connectivity triggers a greater probability of default in the financial system. It also shows that network intensity parameter has an amplifying effect on shocks. It is clear from the bar size that both the weighing matrix and the network intensity parameters have different effects. Although the contribution of the connection matrix is similar, it varies depending on the strength and number of the connections. Thus, our main finding from Fig. 3 is that both network intensity parameters and connection matrix are key ingredients in either increasing or decreasing network exposure.

\subsubsection{Network exposure to common factors}

To investigate the effect of network exposure on common factors, we used slope coefficient betas as the systematic risk of specific country's market portfolios. This is useful to examine the effect of network exposure on both systematic and idiosyncratic volatility. Bali and Cakici (2010) used beta coefficients as the systematic risk of a country's market portfolio to determine whether country-specific risks are priced into the intertemporal capital asset pricing model (ICAPM). They found that country-specific risks are significantly priced into the ICAPM framework.

Table 5 reports country-specific idiosyncratic volatility in all sample periods, estimated in Eq. (10). As noted by Hueng and Yau (2013), these estimates may vary depending on the data used because they are model-dependent. Notably, the country-specific idiosyncratic volatility of emerging markets as greater than those of developed economies is consistent with the findings of Bali and Cakici $(2008,2010)$ and Hueng and Yau (2013). We also observed, on average, that Turkey had high idiosyncratic volatility in the full sample period and also in Phase 1 . These results are consistent with Bali and Cakici (2010) and Hueng and Yau (2013), who determined that Turkey had a higher estimate than other countries in their sample. Interestingly, most countries had greater idiosyncratic estimates in the crisis period. This could be explained by higher uncertainty in the market during the GFC.

Therefore, we will not discuss country-specific idiosyncratic volatilities because our aim is to determine the role of network exposure on both systematic and idiosyncratic components. By assuming the first order neighborhood in Eq. (7), we investigated the effect of network exposure on the structural model. We used the network intensity parameter to capture the strength of the network exposure (network intensity). This coefficient lies between 0 and 1 , where close to 0 implies lower network intensity and close to 1 signifies higher network intensity. The existence of network exposure is captured by the weighting matrix which was row-normalized. The weighting matrix takes the values between 0 and 1 as representing exposure from other markets, where values close to 0 imply less exposure, while close to 1 implies high exposure. We used the weighting matrix constructed from combined Granger 
Table 5 Estimates of idiosyncratic volatilities

\begin{tabular}{|c|c|c|c|c|c|}
\hline Country & All phases & Phase 1 & Phase 2 & Phase 3 & Phase 4 \\
\hline Austria & 0.0179 & 0.0185 & 0.0275 & 0.0151 & 0.0110 \\
\hline Belgium & 0.0359 & 0.0281 & 0.0324 & 0.0114 & 0.0098 \\
\hline Czech Republic & 0.0201 & 0.0235 & 0.0273 & 0.0131 & 0.0083 \\
\hline Denmark & 0.0280 & 0.0279 & 0.0266 & 0.0148 & 0.0127 \\
\hline Finland & 0.0180 & 0.0198 & 0.0225 & 0.0158 & 0.0110 \\
\hline France & 0.0352 & 0.0288 & 0.0217 & 0.0145 & 0.0110 \\
\hline Germany & 0.0219 & 0.0234 & 0.0225 & 0.0128 & 0.0146 \\
\hline Greece & 0.0219 & 0.0552 & 0.0224 & 0.0214 & 0.0240 \\
\hline Hungary & 0.0559 & 0.0701 & 0.0643 & 0.0201 & 0.0156 \\
\hline Ireland & 0.0296 & 0.0261 & 0.0441 & 0.0259 & 0.0115 \\
\hline Italy & 0.0352 & 0.0283 & 0.0237 & 0.0180 & 0.0156 \\
\hline Netherlands & 0.0176 & 0.0141 & 0.0332 & 0.0219 & 0.0108 \\
\hline Norway & 0.0201 & 0.0221 & 0.0284 & 0.0123 & 0.0115 \\
\hline Poland & 0.0983 & 0.1125 & 0.0285 & 0.0155 & 0.0131 \\
\hline Portugal & 0.0147 & 0.0142 & 0.0168 & 0.0166 & 0.0124 \\
\hline Romania & 0.4326 & 0.5782 & 0.0620 & 0.0239 & 0.0084 \\
\hline Spain & 0.0177 & 0.0174 & 0.0212 & 0.0211 & 0.0119 \\
\hline Sweden & 0.0493 & 0.0356 & 0.0238 & 0.0131 & 0.0157 \\
\hline Switzerland & 0.0651 & 0.0404 & 0.0184 & 0.0104 & 0.0102 \\
\hline Turkey & 2.4059 & 3.3873 & 0.0321 & 0.0169 & 0.0205 \\
\hline United Kingdom & 0.0429 & 0.0336 & 0.0190 & 0.0134 & 0.0110 \\
\hline Argentina & 0.1950 & 0.1980 & 0.0595 & 0.0290 & 0.0417 \\
\hline Brazil & 0.0450 & 0.0491 & 0.0562 & 0.0265 & 0.0179 \\
\hline Chile & 0.0122 & 0.0106 & 0.0118 & 0.0116 & 0.0143 \\
\hline Mexico & 0.0283 & 0.0366 & 0.0217 & 0.0143 & 0.0089 \\
\hline Canada & 0.0219 & 0.0150 & 0.0541 & 0.0107 & 0.0098 \\
\hline United States & 0.0734 & 0.0410 & 0.0416 & 0.0121 & 0.0081 \\
\hline Australia & 0.0525 & 0.0312 & 0.0602 & 0.0138 & 0.0089 \\
\hline China & 0.0672 & 0.0398 & 0.0363 & 0.0155 & 0.0222 \\
\hline India & 0.1183 & 0.1525 & 0.0767 & 0.0234 & 0.0087 \\
\hline Indonesia & 0.0418 & 0.0546 & 0.0392 & 0.0180 & 0.0148 \\
\hline Israel & 0.0980 & 0.1307 & 0.0194 & 0.0116 & 0.0068 \\
\hline Japan & 0.0487 & 0.0324 & 0.0358 & 0.0380 & 0.0151 \\
\hline Hong Kong & 0.0572 & 0.0686 & 0.0252 & 0.0128 & 0.0106 \\
\hline Malaysia & 0.0149 & 0.0173 & 0.0253 & 0.0066 & 0.0055 \\
\hline New Zealand & 0.0696 & 0.0345 & 0.0235 & 0.0177 & 0.0110 \\
\hline Pakistan & 0.0714 & 0.0851 & 0.0702 & 0.0216 & 0.0136 \\
\hline Philippines & 0.0854 & 0.0844 & 0.0737 & 0.0208 & 0.0158 \\
\hline Singapore & 0.0227 & 0.0295 & 0.0224 & 0.0087 & 0.0093 \\
\hline South Korea & 0.0334 & 0.0367 & 0.0359 & 0.0141 & 0.0092 \\
\hline Sri Lanka & 0.0562 & 0.0125 & 0.0132 & 0.0521 & 0.0201 \\
\hline Thailand & 0.0627 & 0.0685 & 0.0300 & 0.0463 & 0.0131 \\
\hline Taiwan & 0.0250 & 0.0315 & 0.0241 & 0.0115 & 0.0081 \\
\hline South Africa & 0.0216 & 0.0216 & 0.0275 & 0.0243 & 0.0162 \\
\hline Egypt & 0.0632 & 0.0534 & 0.0877 & 0.0409 & 0.0245 \\
\hline
\end{tabular}

The table reports the idiosyncratic volatilities for all countries in all phases. The period covered in the sample is 1 January 1999-31 December 2017 
causality and DY approach by using the cross-border liabilities. Based on simple continuity, we assumed that the network intensity parameters exert a similar effect on each country. To be precise, we assume this network intensity parameter to be 0.5 , which is related to the mean estimate obtained in Sect. 6. Other studies, including Blasques et al. (2016), found the estimate to be higher (approximately 0.7). Figure 4 shows how the structural model responds to network exposure across the entire sample period. The blue bar represents the structural systematic component, and the yellow bar is the idiosyncratic component. The orange bar is the absolute contribution of network exposure to change in the systematic component while the purple bar is the absolute contribution of network exposure to change in the idiosyncratic component.

Turkey, Romania and Argentina had greater values of idiosyncratic volatility than other economies with smaller estimates. We observed that the systematic component was predominant in most economies compared to the idiosyncratic volatility. The effect of network exposure on systematic component was higher (represented by the size of the orange bars in Fig. 4) than on idiosyncratic component, with the exception of Turkey, Argentina and Romania.

Figure 5 shows the contribution of network exposure on the structural model in different periods. On average, the idiosyncratic volatility of Turkey was still dominant in Phase 1 but reduced in all other phases. We can relate Turkey's high idiosyncratic volatility to the banking crisis that led to capital flight and recession in the economy at the end of 2000. This demonstrates that Turkey's banking crisis was largely idiosyncratic even though it could have been triggered by other external factors. Higher idiosyncratic volatility also explains the ability of Turkey's investors (who are mostly foreign) to diversify their portfolios. Turkey's idiosyncratic volatility seemed to diminish in Phase 2. Surprisingly, we expected it to increase due to the GFC. This may have happened due to Turkey's restructure of its financial system after the banking crisis in 2001.

The results in Phase 1 for all other countries shows that the network contribution to the idiosyncratic component is almost irrelevant. A possible suggestion is that the network exposure has a diversifying effect on the idiosyncratic component. The network contribution to the systematic component was large; thus, it has an amplifying effect on the systematic component. The results in all other phases indicate that network exposure has a greater impact on the systematic component and less impact on idiosyncratic volatility. These results support the notion that network exposure contributes to spreading and diversifying risks.

In general, our contribution highlights the distinction between the spreading and sharing of sharing. From Fig. 5, it can be observed that the presence of network exposure increases systematic risk and reduces idiosyncratic risk. Institutions with increased unsecured borrowing and lending have a higher chance of receiving and spreading shocks to other institutions. Figure 5 also reveals the changing nature of interconnections in the different phases. This is because we used a constant network intensity parameter while changing the connection matrix. Billio et al. (2015) reported similar results in which the presence of network effect increased the systematic component and decreased the idiosyncratic component. With the increase in network intensity parameters (from 0.5 to 0.75 ), the financial system became 

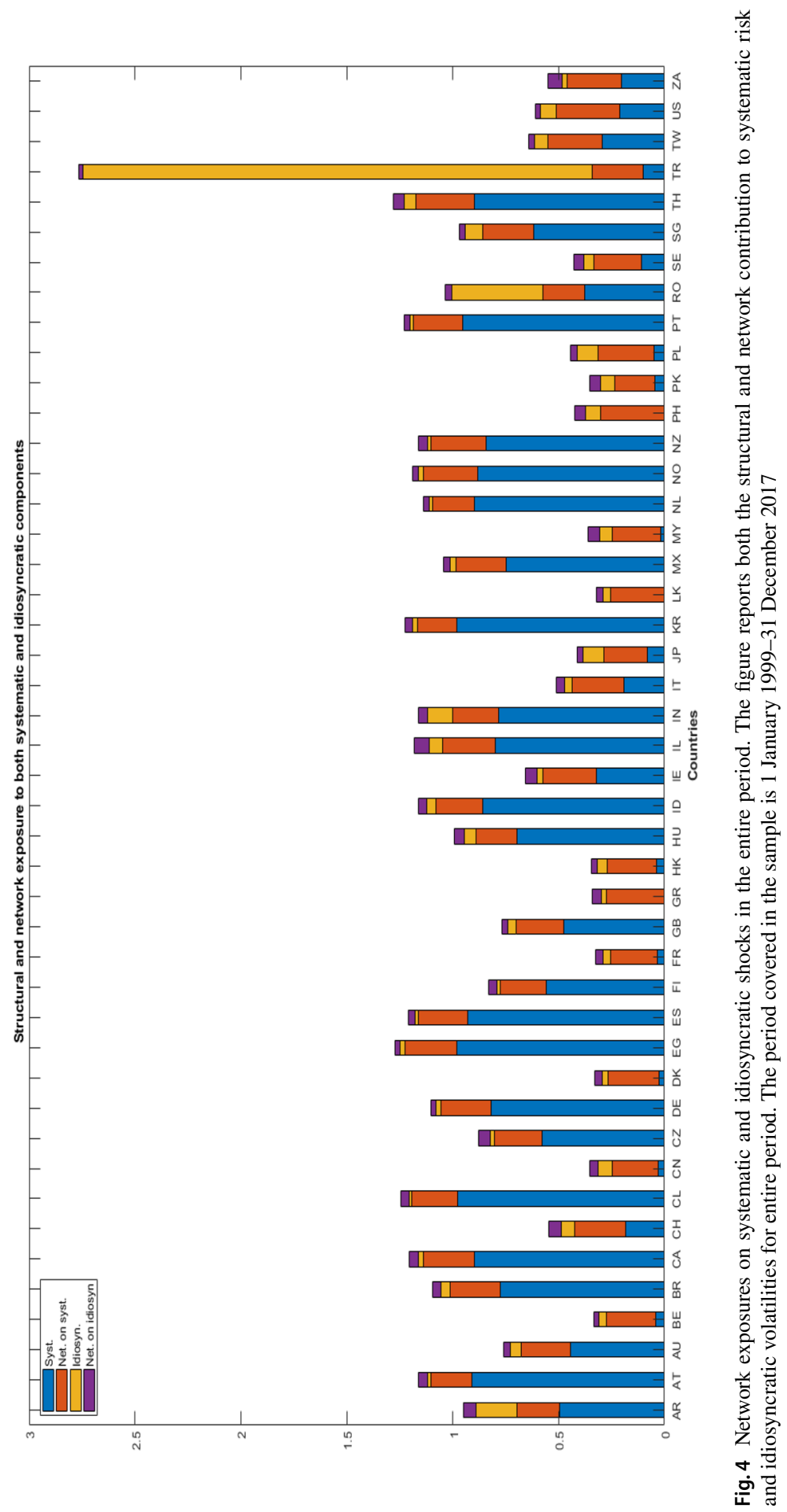


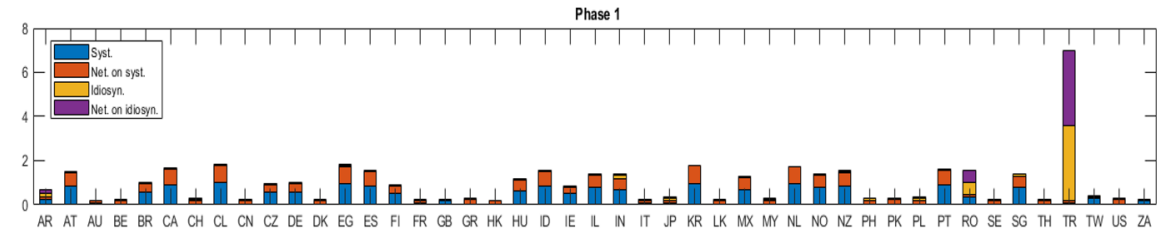

Phase 2

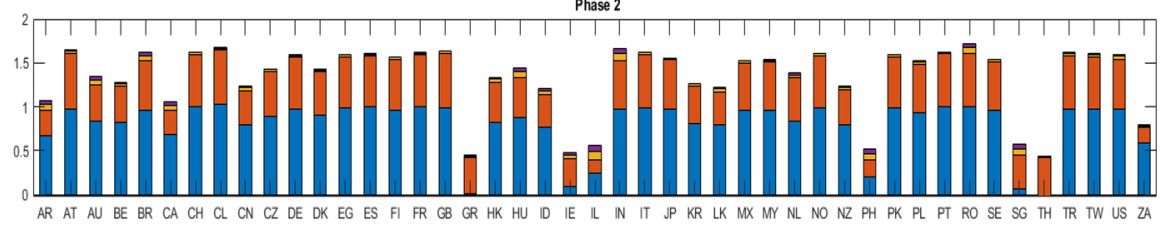

Phase 3

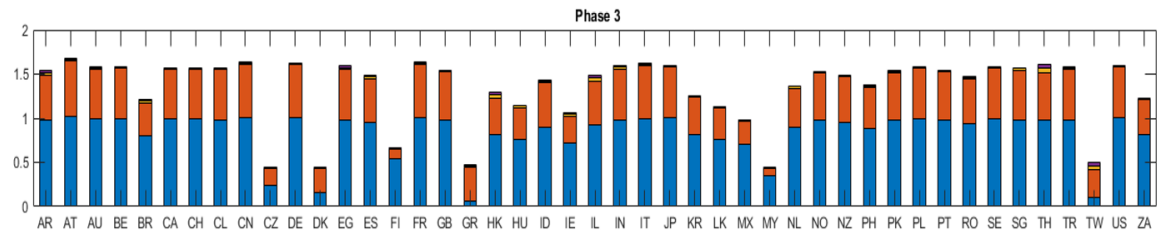

Phase 4

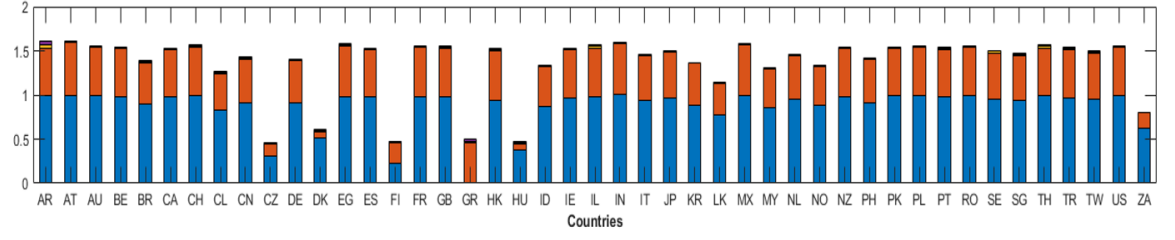

Fig. 5 Network exposures on systematic and idiosyncratic shocks in all the phases. The figures show the contribution of network exposure to both systematic and idiosyncratic volatility in each phase. The period covered in the sample is 1 January 1999-31 December 2017

more vulnerable to shocks and benefited more from diversification. If the network intensity parameter is decreased from 0.5 to 0.25 , there will be a decrease in shock spreading and a reduced diversification effect. These results are consistent with recent studies that showed that the presence of interconnection increases vulnerability in the financial system while also helping to diversify risks. ${ }^{8}$ The results also indicate that network exposure had greater impact in Phases 2, 3 and 4 than Phase 1. This is attributable to the GFC in Phase 2, EDC in Phase 3 and Chinese market crash in Phase 4.

We also investigated the effect of network connectivity on the structural model. For our case, we used a sparse matrix to determine whether a decrease in network connectivity increased or decreased network exposure. We randomly generated the sparse matrix. As shown in Fig. 6, fewer interconnections in the financial system led to a reduction in the size of the bars. This suggests that having fewer interconnections reduces the magnitude of the spread of absorption of shocks .

\footnotetext{
${ }^{8}$ See Acemoglu et al. (2015), Tonzer (2015) and Gai and Kapadia (2010).
} 
Phase 1

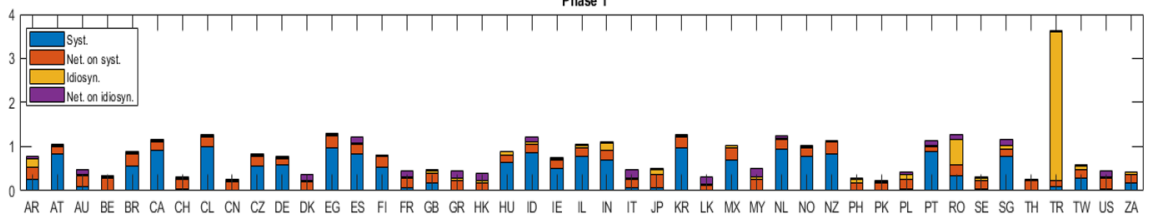

Phase 2

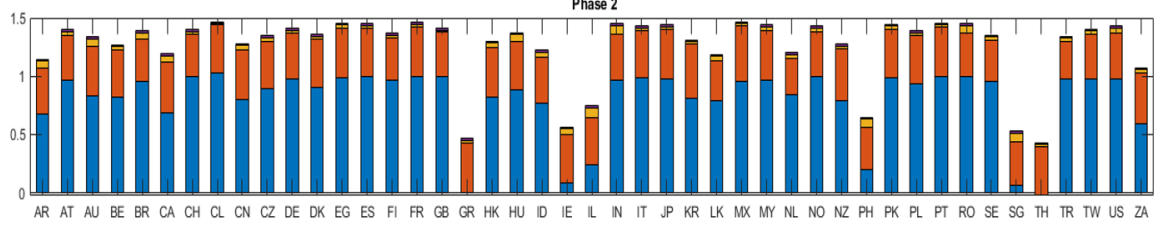

Phase 3

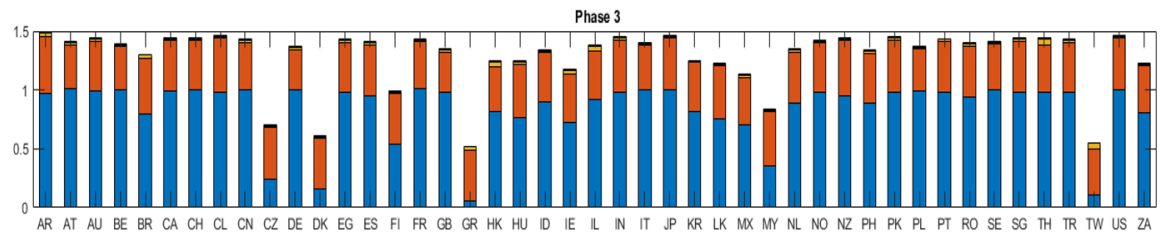

Phase 4

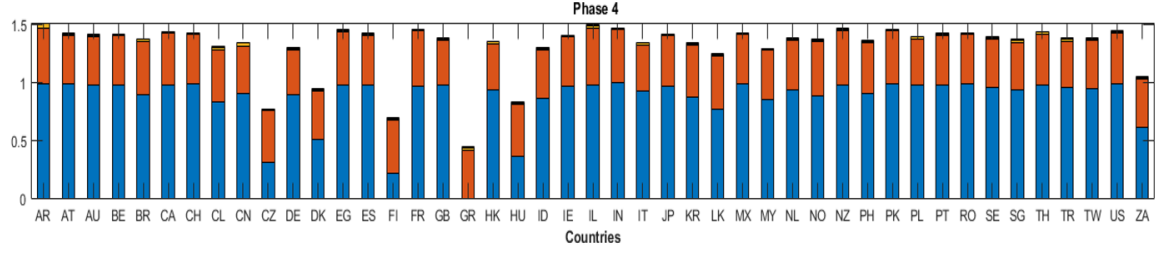

Fig. 6 Effect of network exposures with decreased interconnectedness. The figures show how the contribution of network exposure to both systematic and idiosyncratic volatility changed with reduced interconnections between markets. This involved using a sparse weighting matrix. The period covered in the sample is 1 January 1999-31 December 2017

We also used dense matrix to determine its effect on the structural model. Figure 7 shows the contribution of using denser weighting matrix in all sample periods. This weighting matrix was based on trade linkages. Trade linkages are denser because countries are more interlinked through bilateral trade. This figure shows that more interconnection in the financial system increases the systematic risk and reduces the idiosyncratic component. This implies that using a denser weighting matrix increases the network exposure and amplify shocks as well as diversify some shocks. Overall, our approach shows that an increase in network exposure significantly increases systematic shocks through risk spreading, and reduces idiosyncratic risk through diversification. Further, these results signify that a large degree of connectivity does not necessarily dampen risk exposure, but amplifies shocks in the financial system. This is consistent with Amini et al. (2016), who affirmed that an increase in network connection may lead to systemic instability. 

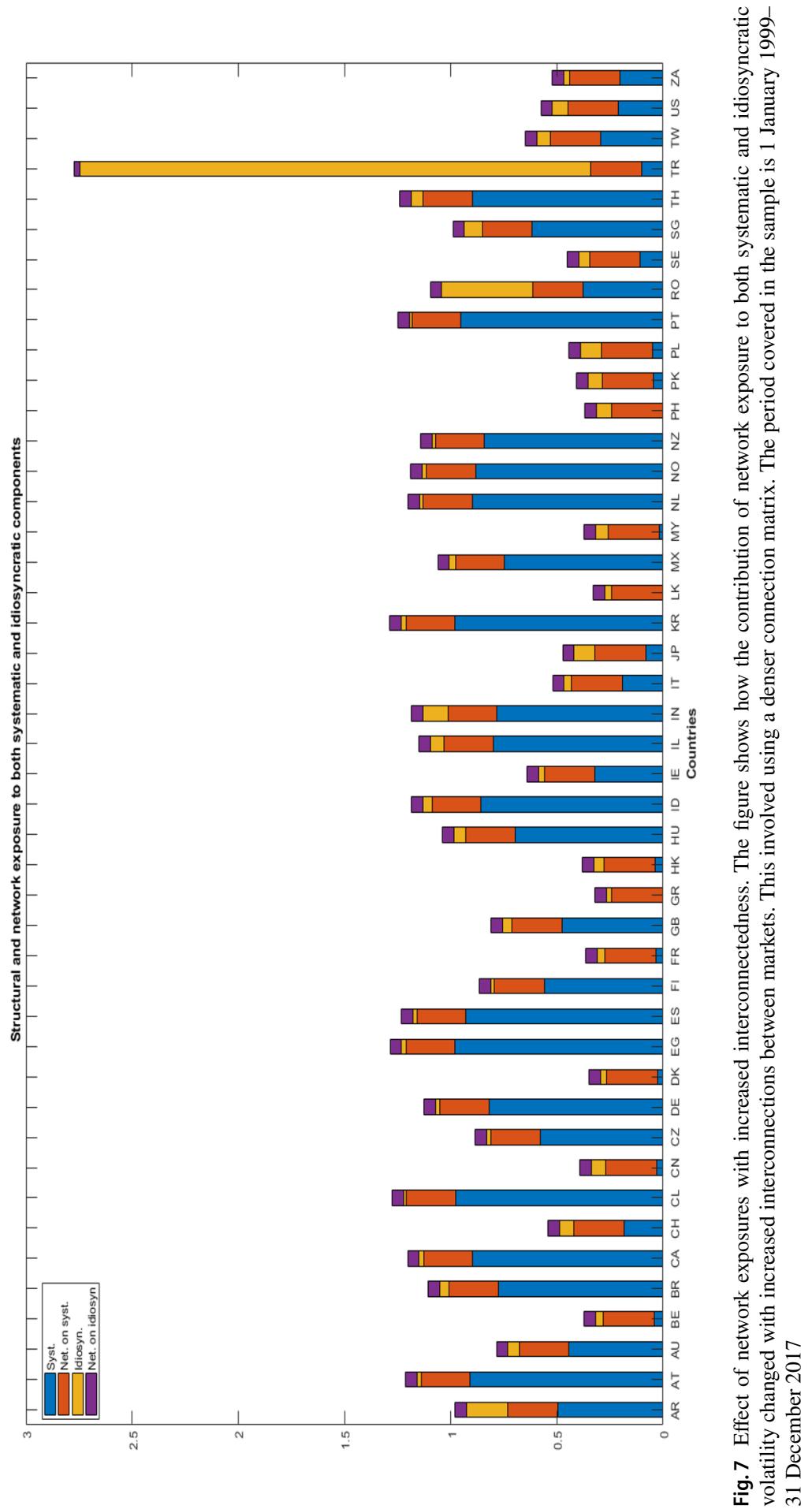


\section{Optimal value of the network intensity parameter}

The next question to address is the estimation of the network intensity parameter $(\rho)$, which captures the strength of the network exposure. This coefficient is also important, as it plays a key role in monitoring network exposure (Sect. 4). Different estimation methods have been proposed to estimate network intensity parameter, including ordinary least squares (OLS), maximum likelihood estimation (MLE), method of moments (MoM), two-stage least squares (2SLS) and the generalized method of moments (GMM).

\subsection{Static network intensity parameter}

We introduce the spatial autoregressive (SAR) model to measure network intensity parameter. We begin by considering a simple first-order (pure) SAR model, where 'pure' refers to the absence of exogenous regressors $\left(X_{n}\right)$ as proposed by Anselin (1988) and is defined as:

$$
y=\rho W y+\varepsilon
$$

where $n$ is the number of observations, $y=\left(y_{1}, y_{2}, \ldots, y_{n}\right)^{\prime}$ is a vector of observations on the dependent variable, $W$ is $n \times n$ exogenous connection matrices, $\rho$ is a scalar representing the network intensity coefficient and $\varepsilon=\left(\varepsilon_{1}, \varepsilon_{2}, \ldots, \varepsilon_{n}\right)^{\prime}$ as a vector of residuals assumed to be independent and identically distributed.

By rearranging Eq. (14), the error term yields:

$$
\varepsilon=y-\rho W y
$$

LeSage and Pace (2009) describe the vector Wy as spatial lag representing a linear combination of the neighboring values to each observation. This is supported by Lee (2007), who shows that the influence in the neighboring asset is due to spatial effects.

Our first estimate of $\rho$ is based on OLS. However, the OLS estimate of $\rho$ is considered biased and inconsistent. Following Anselin (1988), the OLS estimate of $\rho$ is denoted by $\hat{p}$ and given by,

$$
\hat{p}=\left(y^{\prime} W^{\prime} W y\right)^{-1} y^{\prime} W^{\prime} y
$$

An estimate of $\rho$ is unbiased if $E(\hat{p})=p$. We prove below that $E(\hat{p})=p$.

$$
\begin{aligned}
E(\hat{p}) & =E\left[\left(y^{\prime} W^{\prime} W y\right)^{-1} y^{\prime} W^{\prime}(\rho W y+\varepsilon)\right] \\
& =\rho+E\left[\left(y^{\prime} W^{\prime} W y\right)^{-1} y^{\prime} W^{\prime} \varepsilon\right]
\end{aligned}
$$

Therefore, the OLS estimate is biased since the second term in Eq. (17) does not equal $0, E(\hat{p}) \neq p$. To show that the OLS estimate is inconsistent, Anselin (1988) demonstrated that the probability limit (plim) for the term $y^{\prime} W^{\prime} \varepsilon$ is not 0 except in 
trivial cases when $\varepsilon=0 .{ }^{9}$ Since the OLS estimate is biased and inconsistent, we had to consider alternatives to estimate the network intensity parameter.

We first consider the MLE method because of its simplicity. According to LeSage and Pace (2009), the MLE for $\rho$ requires identification of the value of the SAR coefficient that maximizes the likelihood function, given by:

$$
\begin{aligned}
L\left(\sigma^{2} ; \varepsilon\right) & =\frac{1}{2 \Pi \sigma^{2(n / 2)}} \exp \left\{-\frac{1}{2 \sigma^{2}}(y-\rho W y)^{\prime}(y-\rho W y)\right\} \\
L\left(y \mid \rho, \sigma^{2}\right) & =\frac{1}{2 \Pi \sigma^{2(n / 2)}}(J) \exp \left\{-\frac{1}{2 \sigma^{2}}(y-\rho W y)^{\prime}(y-\rho W y)\right\}
\end{aligned}
$$

The Jacobian function can be obtained through the differentiation of Eq. (15) with respect to the dependent variable $y$ yielding:

$$
J=\frac{\partial \varepsilon}{\partial y}=\left|I_{n}-\rho W\right|
$$

where $I_{n}$ is $n \times n$ identity matrix. Substituting Eq. (19) for Eq. (18) gives:

$$
L\left(y \mid \rho, \sigma^{2}\right)=\frac{1}{2 \Pi \sigma^{2(n / 2)}}\left|I_{n}-\rho W\right| \exp \left\{-\frac{1}{2 \sigma^{2}}(y-\rho W y)^{\prime}(y-\rho W y)\right\}
$$

Lee (2002) asserts that deriving the eigenvalue $(\lambda)$ of the connection matrix $W$ simplifies the computation problem. The natural logarithm of Eq. (20) is:

$$
\begin{aligned}
\ln L & =-\frac{n}{2} \ln \left(2 \Pi \sigma^{2}\right)+\ln \left|I_{n}-\rho W\right|-\frac{1}{2 \sigma^{2}}(y-\rho W y)^{\prime}(y-\rho W y) \\
& =-\frac{n}{2} \ln (2 \Pi)-\frac{n}{2} \ln \left(\sigma^{2}\right)+\ln \left|I_{n}-\rho W\right|-\frac{1}{2 \sigma^{2}}(y-\rho W y)^{\prime}(y-\rho W y)
\end{aligned}
$$

The natural logarithm can be further restructured by eliminating the residual parameter, $\sigma^{2}$. This is achieved by substituting with the error term, given by:

$$
\hat{\sigma}^{2}=\frac{1}{n}(y-\rho W y)^{\prime}(y-\rho W y)
$$

This yields to:

$$
\ln L=-\frac{n}{2} \ln (2 \Pi)-\frac{n}{2} \ln (y-\rho W y)^{\prime}(y-\rho W y)+\ln \left|I_{n}-\rho W\right|
$$

The parameter space of $\rho$ requires that the determinants of $I_{n}-\rho W$ to be strictly positive. A univariate optimization problem can be used to maximize the above expression with respect to $\rho$. This implies that the optimal search of $\rho$ estimates take feasible values within the range:

$$
1 / \lambda_{\text {min }}<\rho>1 / \lambda_{\max }
$$

\footnotetext{
${ }_{9}^{9}$ Anselin (1988) shows that $p \lim N^{-1}\left(y^{\prime} W^{\prime} \varepsilon\right)=p l i m N^{-1} \varepsilon^{\prime} W(I-p W)^{-1} \varepsilon$.
} 
where $\lambda_{\text {min }}$ is the minimum eigenvalue of the standardized matrix $W$ while $\lambda_{\text {max }}$ is the largest eigenvalue of the same matrix.

Equation (14) can be extended to investigate how network intensity changes with the presence of exogenous variables. The mixed-SAR model (see LeSage \& Pace, 2009) can be written as:

$$
\begin{aligned}
& y=\rho W y+\beta X+\varepsilon \\
& \varepsilon \sim N\left(0, \sigma^{2} I_{n}\right)
\end{aligned}
$$

where $X=\left(X_{1}, X_{2}, \ldots, X_{n}\right)$ a vector ( $n \times k$, and where $k$ is the number of variables) of observations on the exogenous variables having $\beta=\left(\beta_{1}, \beta_{2}, \ldots, \beta_{k}\right)$ coefficients.

Rewriting Eq. (25) repeatedly yields:

$$
\begin{aligned}
y & =\rho W y+\beta X+\varepsilon \\
& =\rho W y(\rho W y+\beta X+\varepsilon)+\beta X+\varepsilon \\
& =\rho W y(\rho W y(\rho W y+\beta X+\varepsilon)+\beta X+\varepsilon)+\beta X+\varepsilon \\
& =\sum_{n=1}^{\infty}[\rho W]^{n}(\beta X+\varepsilon)
\end{aligned}
$$

Equation (26) clearly shows the effect of the weighting matrix in spreading shocks from one entity to the other until it diminishes leading to a steady-state.

Equation (25) can also be written in a more compact way as:

$$
(I-\rho W) y=\beta X+\varepsilon
$$

which provides a structure to the contemporaneous relationship based on the spatial proximity in association with the SAR model. Thus, the model includes contemporaneous relationships, driven by interconnections across different assets (markets), exogenous regressors and asset (market) specific shocks. Equation (27) is conveniently expressed in compact because our focus is to estimate the network intensity parameter, $\rho$ which captures the endogenous effect of network exposure.

The general idea is to first construct a univariate optimization problem for the parameter $\rho$. Following Anselin (1988) and LeSage and Pace (2009), this is done by maximizing the full likelihood function of the dependent variable with respect to the unknown parameters. This is given by:

$$
L\left(y \mid \rho, \beta, \sigma^{2}\right)=\frac{1}{2 \Pi \sigma^{2(n / 2)}}\left|I_{n}-\rho W\right| \exp \left\{-\frac{1}{2 \sigma^{2}}(y-\rho W y-X \beta)^{\prime}(y-\rho W y-X \beta)\right\}
$$

The natural logarithm function in Eq. (28) can be specified as:

$$
\begin{aligned}
\ln L & =-\frac{n}{2} \ln \left(2 \Pi \sigma^{2}\right)+\ln \left|I_{n}-\rho W\right|-\frac{1}{2 \sigma^{2}} e^{\prime} e \\
& =-\frac{n}{2} \ln (2 \Pi)-\frac{n}{2} \ln \left(\sigma^{2}\right)+\ln \left|I_{n}-\rho W\right|-\frac{1}{2 \sigma^{2}} e^{\prime} e
\end{aligned}
$$

where 


$$
\begin{aligned}
& e=(y-\rho W y-X \beta) \\
& \rho \in\left(\min (\omega)^{-1}, \max (\omega)^{-1}\right)
\end{aligned}
$$

where $\omega$ is the eigenvalue constructed from matrix $W$. The value of $\rho$ is assumed to be bounded between 0 and 1 . Next, we estimate each parameter in Eq. (29). This is done by solving the first-order derivatives of Eq. (29) with respect to the individual parameters.

- Estimate of $\beta$ by differentiating Eq. (29) with respect to $\beta$. We obtain:

$$
\begin{aligned}
\frac{\partial \ln (L)}{\partial \beta} & =0 \\
\frac{\partial \ln (L)}{\partial \beta} & =\frac{\partial\left(\frac{1}{2 \sigma^{2}}(y-\rho W y-X \beta)^{\prime}(y-\rho W y-X \beta)\right)}{\partial \beta} \\
0 & =\frac{\partial\left(\frac{1}{2 \sigma^{2}}(y-\rho W y-X \beta)^{\prime}(y-\rho W y-X \beta)\right)}{\partial \beta} \\
0 & =\frac{1}{2 \sigma^{2}}\left(X^{\prime}(y-\rho W y)-X^{\prime} X \beta\right) \\
\beta & =\left(X^{\prime} X\right)^{-1} X^{\prime}\left(I_{n}-\rho W\right) y
\end{aligned}
$$

From Eq. (30), the estimate of $\beta$ is:

$$
\hat{\beta}=\left(X^{\prime} X\right)^{-1} X^{\prime}\left(I_{n}-\rho W\right) y
$$

For simplicity, this can be written as:

$$
\hat{\beta}=\left(X^{\prime} X\right)^{-1} X^{\prime} y-\rho\left(X^{\prime} X\right)^{-1} X^{\prime} W y
$$

- Estimate of $\sigma^{2}$ we differentiate Eq. (29) with respect to $\sigma^{2}$ to yield:

$$
\begin{aligned}
\frac{\partial \ln (L)}{\partial \sigma^{2}} & =0 \\
\frac{\partial \ln (L)}{\partial \sigma^{2}} & =\frac{\partial\left(-\frac{n}{2} \ln \left(\sigma^{2}\right)+\frac{1}{2 \sigma^{2}}(y-\rho W y-X \beta)^{\prime}(y-\rho W y-X \beta)\right)}{\partial \sigma^{2}} \\
0 & =-\frac{n}{2 \sigma^{2}}+\frac{1}{2\left(\sigma^{2}\right)^{2}}(y-\rho W y-X \beta)^{\prime}(y-\rho W y-X \beta) \\
0 & =-n+\frac{1}{\sigma^{2}}(y-\rho W y-X \beta)^{\prime}(y-\rho W y-X \beta) \\
\sigma^{2} & =\frac{(y-\rho W y-X \beta)^{\prime}(y-\rho W y-X \beta)}{n}
\end{aligned}
$$

Thus, the estimate of $\sigma^{2}$ is given by: 


$$
\hat{\sigma^{2}}=\frac{(y-\rho W y-X \beta)^{\prime}(y-\rho W y-X \beta)}{n}
$$

- Estimate of $\rho$ unlike $\beta$ and $\sigma^{2}$, which have closed form solutions, $\rho$ needs to be estimated using optimization problem that maximizes Eq. (29) with respect to $\rho$. By replacing estimates of $\beta$ and $\sigma^{2}$ in Equation (29) and letting $\hat{\delta}_{0}=\left(X^{\prime} X\right)^{-1} X^{\prime} y, \hat{\delta}_{d}=\left(X^{\prime} X\right)^{-1} X^{\prime} W y$ in Eq. (32), we have:

$$
y=X \hat{\delta}_{0}+\hat{e}_{0} \quad \text { and } \quad W y=X \hat{\delta}_{d}+\hat{e}_{d}
$$

which can be estimated by OLS. Thus, Eq. (32) can be rewritten as:

$$
\begin{aligned}
\hat{\beta} & =\left(X^{\prime} X\right)^{-1} X^{\prime} y-\rho\left(X^{\prime} X\right)^{-1} X^{\prime} W y \\
& =\hat{\delta}_{0}-\rho \hat{\delta}_{d}
\end{aligned}
$$

The error term from Eq. (35) can be given by: $\hat{e}_{0}=y-X \hat{\delta}_{0}$ and $\hat{e}_{d}=W y-X \hat{\delta}_{d}$. Substituting to $\sigma^{2}$ yields

$$
\sigma^{2}=\frac{\left(e_{0}-\rho e_{d}\right)^{\prime}\left(e_{0}-\rho e_{d}\right)}{n}
$$

Using the results of $\beta$ and $\sigma^{2}$, Eq. (29) becomes:

$$
\begin{aligned}
\ln L= & -\frac{n}{2} \ln (2 \Pi)-\frac{n}{2} \ln \left(\frac{\left(e_{0}-\rho e_{d}\right)^{\prime}\left(e_{0}-\rho e_{d}\right)}{n}\right) \\
& +\ln \left|I_{n}-\rho W\right|-\frac{1}{2} \\
= & -\frac{n}{2} \ln (2 \Pi)-\frac{n}{2} \ln \left(\left(e_{0}-\rho e_{d}\right)^{\prime}\left(e_{0}-\rho e_{d}\right)\right)-\frac{n}{2} \ln (n) \\
& +\ln \left|I_{n}-\rho W\right|-\frac{1}{2}
\end{aligned}
$$

which can be written as:

$$
\begin{aligned}
& =c-\frac{n}{2} \ln \left(\left(e_{0}-\rho e_{d}\right)^{\prime}\left(e_{0}-\rho e_{d}\right)\right)+\ln \left|I_{n}-\rho W\right| \\
c & =-\frac{n}{2} \ln (2 \Pi)-\frac{n}{2} \ln (n)-\frac{1}{2}
\end{aligned}
$$

Thus, to obtain the estimates of $\rho$, we need to simplify the log-likelihood with respect to the scalar $\rho$ and optimize the following equation:

$$
\left(\begin{array}{c}
f\left(\rho_{1}\right) \\
f\left(\rho_{n}\right) \\
\vdots \\
f\left(\rho_{r}\right)
\end{array}\right)=\left(\begin{array}{c}
c-\frac{n}{2} \ln \left(\left(e_{0}-\rho_{1} e_{d}\right)^{\prime}\left(e_{0}-\rho_{1} e_{d}\right)\right)+\ln \left|I_{n}-\rho_{1} W\right| \\
c-\frac{n}{2} \ln \left(\left(e_{0}-\rho_{2} e_{d}\right)^{\prime}\left(e_{0}-\rho_{2} e_{d}\right)\right)+\ln \left|I_{n}-\rho_{2} W\right| \\
\vdots \\
c-\frac{n}{2} \ln \left(\left(e_{0}-\rho_{r} e_{d}\right)^{\prime}\left(e_{0}-\rho_{r} e_{d}\right)\right)+\ln \left|I_{n}-\rho_{r} W\right|
\end{array}\right)
$$




\subsection{Dynamic network intensity parameter}

The static SAR model specified in Eq. (25) can be further extended to a dynamic SAR. This allows estimation of a time-varying network intensity parameter $\left(\rho_{t}\right)$. This is useful in understanding how the spatial parameter changes over time. As pointed out by Blasques et al. (2016), time-varying network intensity parameters indicate how the spillover changes over time. We considered the case when we have constant volatility.

A time-varying SAR model with constant disturbances is defined as:

$$
\begin{aligned}
y_{t} & =\rho_{t} W y_{t}+\beta X_{t}+\varepsilon_{t} \\
\varepsilon_{t} & \sim N(0, \Sigma), \quad t=1,2, \ldots, T
\end{aligned}
$$

where $\Sigma$ is constant over time.

Assuming constant disturbances allows us to investigate how the spatial parameter changes over a specific point in time. This is an important aspect of examining financial systems in which the volatility of returns is known to vary considerably between non-crisis and crisis periods (Blasques et al., 2016; Catania \& Billé, 2017). The diagonal elements represent the time-conditional variances of the cross-sectional independent innovation at any given point in time. We impose diagonality assumption as the standard constant conditional correlation (CCC) and dynamic conditional correlation (DCC) model proposed by Engle (2002).

The generalized log-likelihood function of the constant $\left(L c_{t}\right)$ variance models becomes:

$$
\ln L c_{t}=-\frac{n}{2} \ln (2 \Pi)-\frac{n}{2} \ln (\Sigma)+\sum_{t=1}^{T} \ln \left|I_{n}-\rho_{t} W\right|-\frac{1}{2} e_{t}^{\prime} \Sigma^{-1} e_{t}
$$

where

$$
\begin{aligned}
e_{t} & =\left(y_{t}-\rho_{t} W y_{t}-X_{t} \beta\right) \\
& \rho_{t} \in\left(\min (\omega)^{-1}, \max (\omega)^{-1}\right)
\end{aligned}
$$

Allowing for time-varying variance in the shocks led to the following:

$$
y_{t}=\rho_{t} W y_{t}+\beta X_{t}+\varepsilon_{t}
$$

where

$$
\begin{aligned}
\varepsilon_{t} & \sim N\left(0, \Sigma_{t}\right), \quad t=1,2, \ldots, T \\
\Sigma_{t} & \sim \operatorname{diag}\left(\sigma_{1}^{2}, \sigma_{2}^{2}, \cdots, \sigma_{t}^{2}\right)
\end{aligned}
$$

The generalized log-likelihood function of the time-varying $\left(L v_{t}\right)$ variance models becomes:

$$
\ln L v_{t}=-\frac{n}{2} \ln (2 \Pi)-\frac{n}{2} \ln \left(\Sigma_{t}\right)+\sum_{t=1}^{T} \ln \left|I_{n}-\rho_{t} W\right|-\frac{1}{2} e_{t}^{\prime} \Sigma_{t}^{-1} e_{t}
$$


Table 6 Network intensity estimates and their robust standard errors

\begin{tabular}{llllll}
\hline & All phases & Phase 1 & Phase 2 & Phase 3 & Phase 4 \\
\hline Whole sample & $0.5072(0.0043)$ & $0.4727(0.0059)$ & $0.6134(0.0142)$ & $0.5495(0.0099)$ & $0.5110(0.0091)$ \\
Advanced & $0.5292(0.0042)$ & $0.5014(0.0059)$ & $0.5919(0.0144)$ & $0.5664(0.0097)$ & $0.5378(0.0089)$ \\
Emerging & $0.3125(0.0040)$ & $0.2804(0.0054)$ & $0.4232(0.0147)$ & $0.3379(0.0095)$ & $0.3236(0.0084)$ \\
Europe & $0.5281(0.0043)$ & $0.5018(0.0059)$ & $0.6196(0.0147)$ & $0.5651(0.0099)$ & $0.5232(0.0092)$ \\
All America & $0.3497(0.0040)$ & $0.3327(0.0056)$ & $0.4447(0.0149)$ & $0.3758(0.0098)$ & $0.3321(0.0081)$ \\
Asia & $0.3515(0.0041)$ & $0.3132(0.0055)$ & $0.4466(0.0148)$ & $0.4068(0.0097)$ & $0.3569(0.0084)$
\end{tabular}

The table reports the estimated network intensity and their robust standard errors in parentheses for the static SAR model. The period covered in the sample is 1 January 1999-31 December 2017

where

$$
\begin{aligned}
e_{t} & =\left(y_{t}-\rho_{t} W y_{t}-X_{t} \beta\right) \\
& \rho_{t} \in\left(\min (\omega)^{-1}, \max (\omega)^{-1}\right)
\end{aligned}
$$

\section{Empirical analysis}

We use the MLE method to estimate the values of $\rho$. MLE is preferred over OLS because of the limitations of OLS as discussed in Sect. 5.1. Despite the known limitations of OLS in estimating $\rho$, Elhorst (2010) stated that the OLS estimate of $\rho$ could serve as a guide of the expected true value. The initial OLS estimate of $\rho$ for our data was 0.5327 . Therefore, it is expected that the optimal value of the estimate of $\rho$ will be within this range. Next, we estimate $\rho$ using the MLE and allow the search to be within the range $1 / \lambda_{\min }-1 / \lambda_{\max }$. The $y$ vector is the average return of each country in our sample over the entire sample period, while we constrained $W$ to lie within the interval $\{0,1\}$ through the process of row standardization; using the row-normalized contiguity matrix of weights ensures that each row of the matrix sums to unity. The row-normalized matrix represents the portion of total liability that the source country/institution shares among its target nodes.

By estimating static network intensity parameter using a pure SAR model (Eq. 21), we ensure consistency with the extant spatial literature (Asgharian et al., 2013; Fernandez, 2011). The static network intensity parameter (which captures the endogenous effect of network exposure) is estimated at each phase. We begin the estimation by excluding additional explanatory variables. Table 6 contains the static network intensity estimates with their corresponding standard errors in parentheses. The estimate for the whole sample was 0.5072 with a small standard error of 0.0043 . This is close enough to the estimate obtained using OLS (0.5327) and represents the potential impact of the parameter on the entire network. Comparing estimates in the different phases, the network intensity parameter was higher in Phase 2 (0.6134). From Fig. 8, we observed a more than $30 \%$ increase in the estimate from Phase 1 


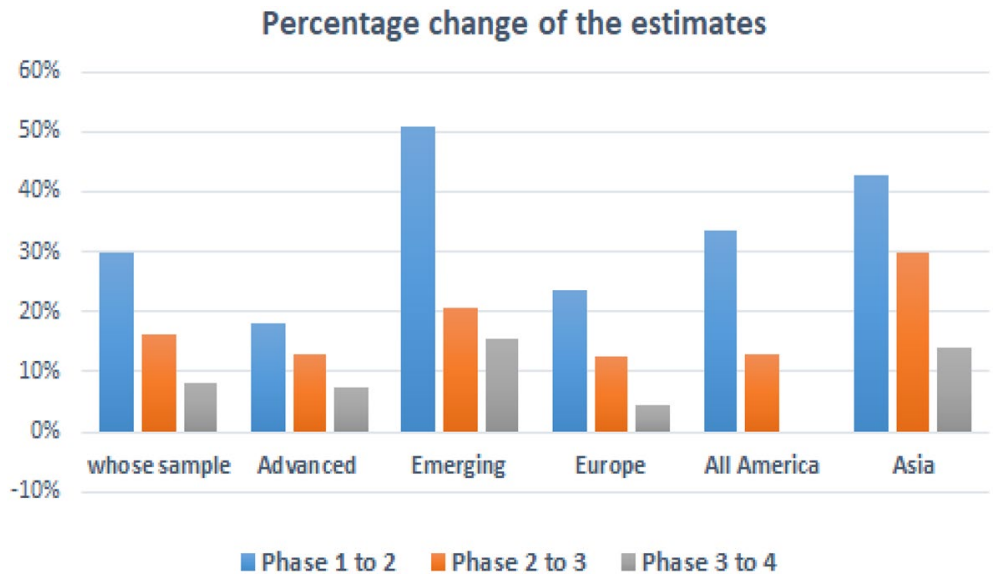

Fig. 8 Change in network intensity estimates in subsequent phases. The figure reports the percentage change of network intensity estimates in the subsequent phases. The entire period covered in the sample is 1 January 1999-31 December 2017

to 2 . It only increased by $16 \%$ in Phase 3 which is approximately half the increase reported for Phase 2.

From the static network intensity results in Table 6 and Fig. 8, it is evident that network intensity increased drastically in Phase 2 (corresponding to the GFC), followed by in phase 3 (associated with the EDC) compared to the other two phases. This is consistent with the finding of Blasques et al. (2016), who used the CDS data of big players in Europe to show that network intensity is higher when the financial system is under stress, suggesting higher spillover in the financial system. Our results also reveal that the GFC, which is associated with large network intensity, had a severe impact on the entire financial system compared to the EDC. The GFC spread throughout the entire network while the EDC severely affected only European countries.

Overall, we can conclude that increases in network intensity estimate could be associated with periods when the financial system is under stress. This is in line with Hypothesis 1, which states that higher network intensity could be associated with crises. For instance, higher estimates in Phase 2 corresponded to GFC; in Phase 3, they could be associated with the EDC. Finally, in Phase 4, they could correspond to the Chinese market crash of 2015 (Alter \& Beyer, 2014; Black et al., 2016; Yu et al., 2017).

The increase in the estimate during times of stress could have an economic effect. Large network intensity estimates are assumed to signify higher propagation strength of a shock to the entire system. This is because of high interconnectedness, which increases network exposure, and thus, may increase fragility in the financial system (Minoiu \& Reyes, 2013). We can relate this to the findings of Tonzer (2015) and argue that high network intensity is associated with increased cross-border 

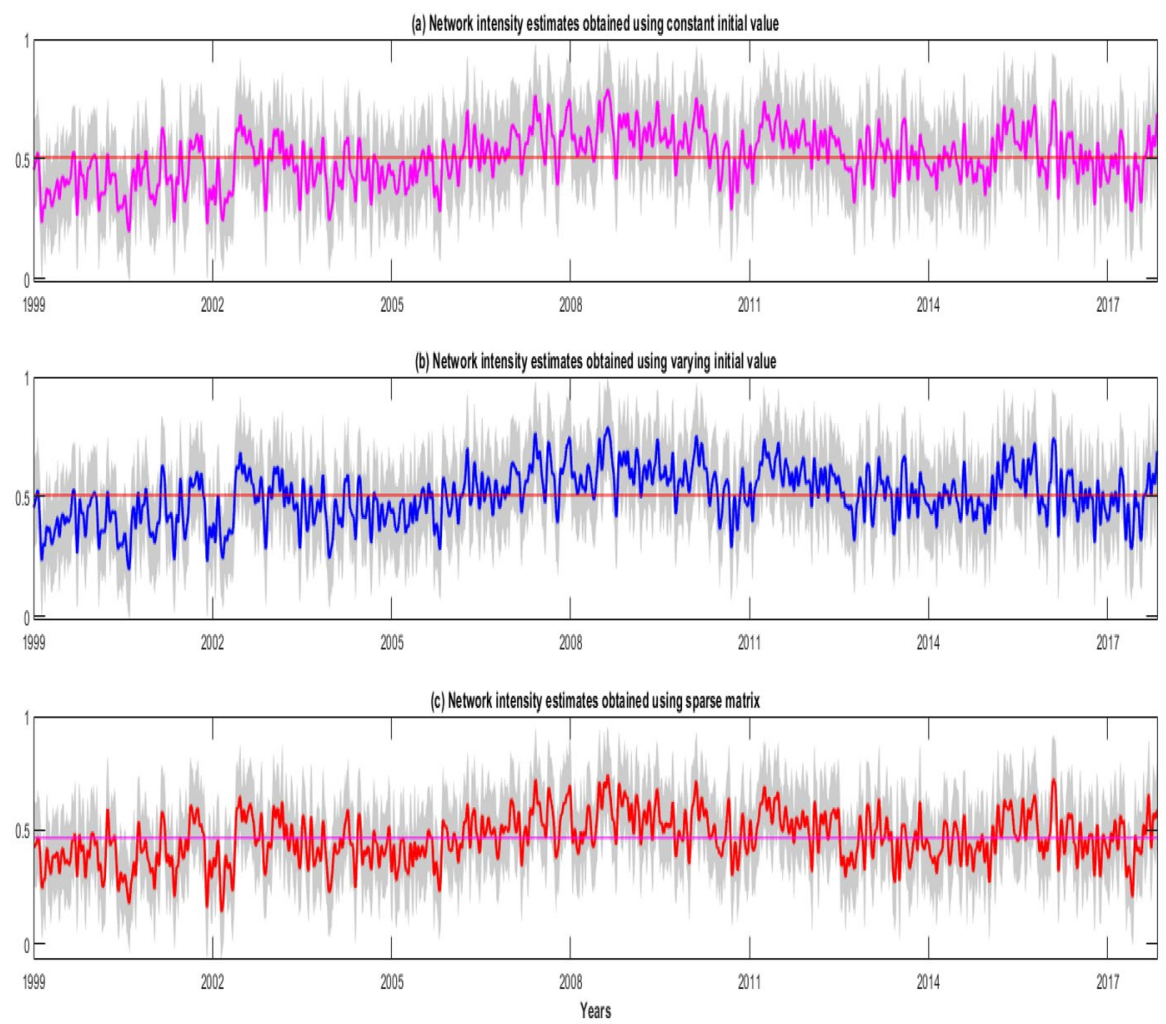

Fig. 9 Network intensity estimates for the entire period. The figures display the network effect for the whole sample period without regressors. The light areas are the $95 \%$ confident intervals with the horizontal line representing average estimate in the whole period. Figure 9 a presents the dynamic estimates obtained with an assumption of constant $(\rho=0.5)$ initial value while Fig. 9b displays the estimates obtained using changing initial value (it follows $\rho_{t}=0.5+0.4 * \cos (2 \pi t / 200)$ ). Figure 9c presents network intensity estimates using sparse matrix. The period covered in the sample is 1 January 1999-31 December 2017

exposures. ${ }^{10}$ Our findings are also similar to those of Cao et al. (2017), who found that cross-border linkages tend to increase during crises. This could be a signal of greater propagation of shock when institutions are under distress.

To capture the dynamics of the network intensity parameter, we conduct an estimation using a 251-day (one-year horizon) rolling window. We investigate how network intensity changed over time. A one-year period is assumed to be adequate to capture any significant change in economies. Before estimating the parameter, it would be interesting to determine if the estimates differed using a constant initial value of $\rho$ and a changing initial value of $\rho$ at each point in time (the initial value will be used as the starting values in search of the real values in our

\footnotetext{
10 Tonzer (2015) argues that the foreign exposure during the GFC increased in the banking sector, leading to risk spreading through the interconnected links in the financial system.
} 
optimization problem). To proxy the initial changing values of $\rho$, we assume the pattern of the network intensity parameter to be same as those used by Blasques et al. (2016). ${ }^{11}$ Specifically, we assumed the following: constant $\left(\rho_{t}=0.5\right)$, sine $\left(\rho_{t}=0.5+0.4 * \cos (2 \pi t / 200)\right.$, fast sine $\left(\rho_{t}=0.5+0.4 * \cos (2 \pi t / 20)\right.$ and step $\left(\rho_{t}=0.9-0.5 *(k>500)\right)$. We estimate the network intensity parameters by both excluding and including the additional explanatory regressors.

The evolution of the network intensity parameter for the whole sample with the 95\% confidence intervals are presented in Fig. 9a-c. In terms of whether using the different initialization of $\rho$ within the range of 0 and 1 leads to different estimates, our results indicate that dynamic network intensity estimates are identical when using any specification of $\rho$ within $(0,1)$. Next, we investigate whether using varying initial values of $\rho$ would result in different estimates of the network intensity coefficient. The results in Fig. 9a and b show that both initializations of $\rho$ produce similar plots. The implication here is that dynamic network intensity estimates does not necessarily depend on the initial value of $\rho$.

Figure $9 \mathrm{a}$ and $\mathrm{b}$ clearly show that the network intensity parameter changes over time. This is consistent with other studies, such as Forbes and Rigobon (2002), who stated that spillover is time variant. We also observed that estimates oscillated between 0.2 and 0.8 , which signifies a higher variation of propagation chance of shock hitting specific nodes in the network. There is a notable repetition of similar trends of network intensity estimates in that estimates were lower before a crisis and increased during the crisis. This is an indicator of higher propagation of shocks to the system. This finding supports Hypothesis 1, which associates high network intensity to periods of stress, which could be due to increased interconnectedness resulting in fragility of the entire financial system.

In general, higher network intensity estimates in Fig. 9a and b coincide with past major events in the financial sector that include:

- the dot-com bubble in 2002

- the second war in Iraq in 2003

- the GFC between 2007 and 2009

- the EDC in May 2010

- the rapid fall of prices of gold in early 2013

- Chinese stock market turbulence in 2015.

These results imply that network intensity tends to increase during times of stress, which could be associated with an increase in interconnectedness in the financial system (Geraci \& Gnabo, 2018). Additionally, the results indicate financial contagion inthe financial system (Hung, 2021). These findings are supported by Blasques et al. (2016), who related high network intensity to increased spillover in the financial system. These findings are similar to Cao et al. (2017), who reported that crossborder linkages tend to increase during crisis periods. Conversely, larger network intensity-especially during times of stress-are associated with increased crossborder lending, which results in transmission of stronger shocks between markets.

11 See Appendix A.4 for more details on the patterns of the network intensity parameter. 
Previous research by Tonzer (2015) and Sun and Chan-Lau (2017) supports this reasoning. They found that foreign exposures play a significant role in spreading risk. This implies that countries are exposed more to more risks due to large exposure from trading partners. The high network intensity across markets signifies the strong exposure of a shock to the entire financial system (Forbes \& Rigobon, 2002).

To check Hypothesis 2, we use an alternative sparse matrix to estimate network intensity parameter. The sparse matrix provides us with an idea of how the degree of interconnection in a financial system affects estimation of network intensity parameter. We use a randomly generated sparse network matrix with the exception of main diagonal taking zeros. Figure 9c shows the dynamic estimates of the network intensity parameter obtained using sparse matrix with $95 \%$ confidence intervals. From this figure, we observe that network intensity estimates shift downwards when sparse weighting matrix is used. The dynamics of network intensity in Fig. 9c differ from those in Fig. 9a. The results also indicate that interconnectedness among financial markets changes the patterns of network intensity over time. A more stable economy with higher network connectivity would be beneficial in shock absorption, leading to a more resilient financial system. The converse is also true. Further, these results imply that as the degree of connectivity increases (decreases), then network intensity parameter shifts upwards (downwards). As a result, the degree of interconnection plays a key role in the estimation of network intensity parameters. These findings are consistent with previous studies. For instance, Silva et al. (2016) found that shocks spread from highly interconnected networks, leading to financial distress in the entire financial system. This is also supported by Amini et al. (2016), who showed that financial market with larger connections is associated with spreading shocks in the network, leading to financial instability. As Minoiu and Reyes (2013) described the financial network as volatile, we expect this to have an impact on the estimation of network intensity parameters.

To obtain a clearer picture of the evolution of network intensity, we obtain the values of the estimates at each phase. Figure 10 displays the dynamic network intensity coefficients at each phase. From these, we draw a similar conclusion those drawn from the static estimates. On average, these estimates are lower in Phase 1 than in other phases, and increase in Phase 2. The network intensity parameter remains higher in Phase 3 (after the crisis and during the EDC). This suggests that network intensity tends to be higher when the market is under stress. Blasques et al. (2016), who used European CDS data, arrived at a similar conclusion.

\subsection{Impact of exogenous factors on the estimation}

Next, we investigate the marginal effects of the explanatory variables on the estimation of network intensity (Eq. 28). The beta coefficient of the model represents the exogenous exposure to the common factors, while the network intensity parameter captures the endogenous effect of the network exposure in the model. All these external regressors are country-specific. They include volatility index, FX and IR. Volatility index captures the change in risk appetite, which gauges the overall market sentiment. It is measured using the implied volatility of the world index. We 


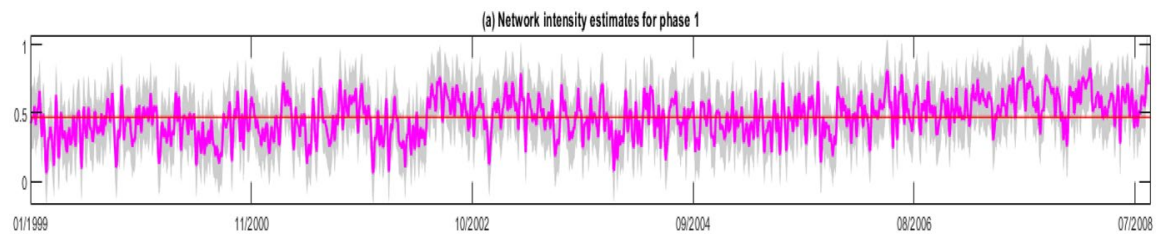

(b) Network intensity estimates for phase 2
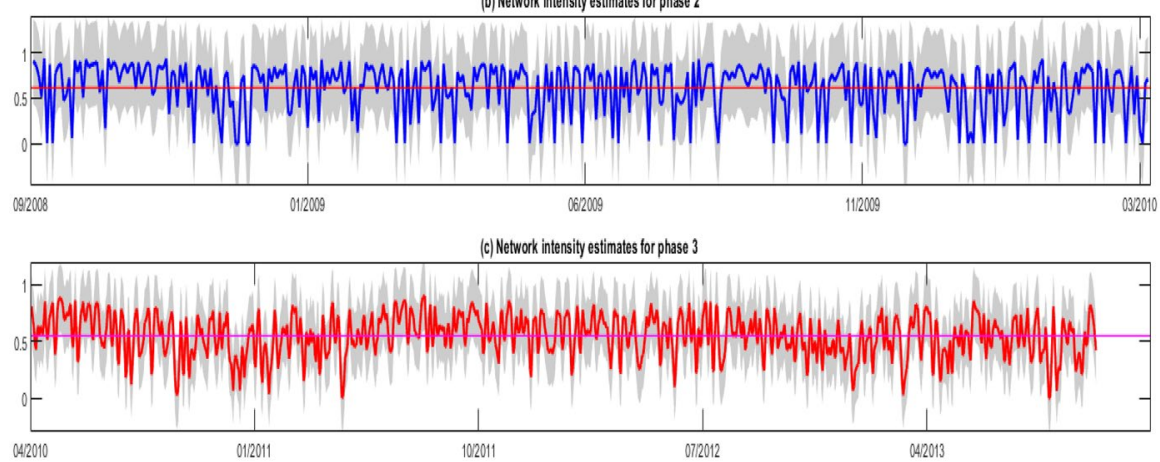

(d) Network intensity estimates for phase 4

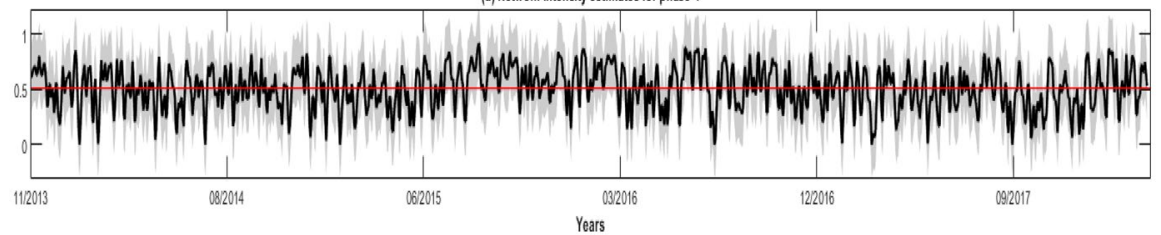

Fig. 10 Network intensity estimates in different phases. The plots display the network effect for the whole sample period in each phase. The light areas are the $95 \%$ confident intervals while the horizontal line is the is the average estimate in the entire period. The period covered in the sample is 1 January 1999-31 December 2017

considered implied volatilities of two major stock indices, VIX and VSTOXX, because of the unavailability of individual country data.

Figure 11 shows the trend of the implied volatility of these stock indices. We use these two major implied volatility indices to investigate the impact on network intensity estimation. It can be observed in Fig. 11 that the implied volatility depicts similar patterns. For example, during the GFC of 2007-2009, the two indices reached their peak over the whole period. We also observe a comparable shift in the magnitude of volatility at different points in time. High spikes in the implied volatility were associated with periods when financial markets were under stress. For instance, the spikes in 2002 are associated with the dot-com bubble, those in 2003 are associated with war in Iraq (Degiannakis et al., 2018), 2007-2009 spikes were associated with the GFC, 2010 spikes with the EDC, 2013 with the rapid fall of prices of gold and 2015 with turbulence in the Chinese stock market.

The country-specific regressors include IR and FX. Local market returns measure the growth of the economy of any country; this measures the stability of a country's economic outlook. IR affects the cost of borrowing; higher IRs are associated with 


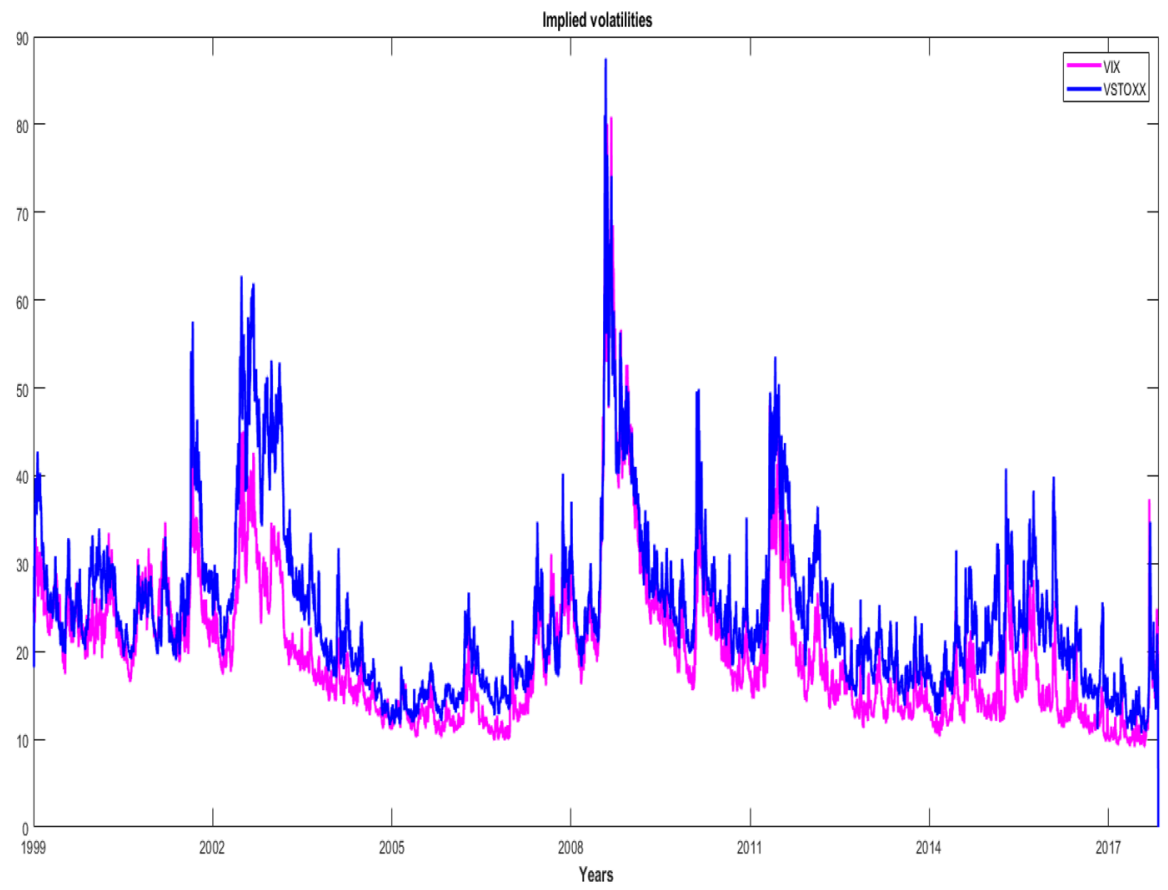

Fig. 11 Volatility estimates. The figures display the implied volatilities for VIX and VSTOXX indices during the entire period. The period covered in the sample is 1 January 1999-31 December 2017

increases in borrowing costs. In addition, IR measures financial integration because it reflects capital movement between countries (Asgharian et al., 2013). We use the absolute changes of 90 days' T-Bills as a proxy for IRs. FX involves trading currencies across the global market. This may affect international trade and capital flows, thereby affecting the economy. Research has found that sudden change in exchange rates have implications for the entire financial system (Flood \& Garber, 1984; Krugman, 1979; Salant \& Henderson, 1978). This fluctuation in exchange rate is associated with currency crisis (Frankel and Rose, 1996). Following the approach used in Asgharian et al. (2013), we use exchange rate volatility, which is computed as the standard deviation of daily log changes in bilateral exchange rates. All these variables are indicators of financial integration and thus may either directly or indirectly have an effect on estimating the network intensity parameter. Daily data for these explanatory variables were obtained from Thompson Reuters' Datastream. The sample consists of 45 countries and the period is January 1999-December 2017; we exclude the weekends.

The estimates shown in Table 7 represent the mean value of the network intensity parameter in the whole sample period. Both liability and trade weighting matrix were used to estimate the static network intensity parameter. These results show that the estimate is greater $(0.5149)$ when additional regressors are excluded than when they are included (0.1933). 
Table 7 Comparison of network intensity estimates with and without regressors

\begin{tabular}{|c|c|c|c|c|c|c|}
\hline & Base & IR & $\mathrm{FX}$ & VIX & All regr. & VSTOXX \\
\hline \multicolumn{7}{|c|}{ Liability matrix } \\
\hline Est. Par. & $\begin{array}{l}0.5149 \\
\quad(0.0042)\end{array}$ & $\begin{array}{l}0.5117 \\
\quad(0.0042)\end{array}$ & $\begin{array}{l}0.5166 \\
\quad(0.0042)\end{array}$ & $\begin{array}{l}0.1055 \\
\quad(0.0027)\end{array}$ & $\begin{array}{l}0.1933 \\
\quad(0.0039)\end{array}$ & $\begin{array}{l}0.0978 \\
\quad(0.0025)\end{array}$ \\
\hline \multicolumn{7}{|c|}{ Trade matrix } \\
\hline Est. Par. & $\begin{array}{l}0.5698 \\
\quad(0.0041)\end{array}$ & $\begin{array}{l}0.5669 \\
\quad(0.0042)\end{array}$ & $\begin{array}{l}0.5718 \\
\quad(0.0041)\end{array}$ & $\begin{array}{l}0.1781 \\
\quad(0.0038)\end{array}$ & $\begin{array}{l}0.2000 \\
\quad(0.0040)\end{array}$ & $\begin{array}{l}0.1617 \\
\quad(0.0036)\end{array}$ \\
\hline
\end{tabular}

The table reports the comparison in network intensity parameter with and without regressors. These estimates are obtained using a dynamic SAR model and they represent the mean values of the whole sample period. The estimates represent the average value of the estimate in the whole sample period. Base are the estimates obtained without including external regressors, All regr. are estimates obtained with inclusion of all other regressors, excluding the VSTOXX index. The other estimates are based on individual regressors

This is an approximately $62 \%$ change (decrease) in the estimate when all additional regressors are included in the estimation. Therefore, the presence of explanatory variables has a discernible effect on the estimation of the network intensity parameter. This suggests that each additional regressors may have either positive or negative effects on the estimation. We observe that the introduction of each variable separately has an effect on network intensity estimate.

Although there is no significant difference between the network intensity estimates with and without inclusion of IR and FX, it is worth discussing their impact on the estimation. IRs across countries may fluctuate due to the FX. Higher IR fluctuations may have a greater impact on network intensity estimates. This is because increases in IR volatility increases uncertainty, which create a channel through which shocks can spread in financial markets (Edwards et al., 1998). This may lead to an increase or decrease in network intensity parameter. Our results reveal that the IR fluctuations lead to decrease in network intensity of $0.6 \%$. FX rates differ from country to country, and this may affect the borrowing rates of each country (Bruno \& Shin, 2014). A more volatile exchange rate increases currency risk premium, and thereby effecting financial market co-movements (Asgharian et al., 2013). This suggests that FX may have a greater impact on estimation. From the static results, we observe that, on average, the volatility in exchange rate leads to an increase in network intensity parameter of $0.3 \%$.

Volatility (the amount of uncertainty regarding change in each stock market index) has a greater impact on network intensity estimation. As displayed in Fig. 11, fluctuations in the implied volatility index, especially during periods of stress, cause shifts in network intensity. High fluctuations in volatility result, on average, in a decrease in network intensity parameter by approximately $80 \%$ in the case of VIX and $81 \%$ for VSTOXX. Both VIX and VSTOXX have almost similar effects on network intensity parameter. Based on these results, we conclude that implied volatility has a major impact on the estimation of the network intensity parameter and would have discernible effects on the financial system. This is supported by Antonakakis et al. (2013), who showed that implied volatility, for 

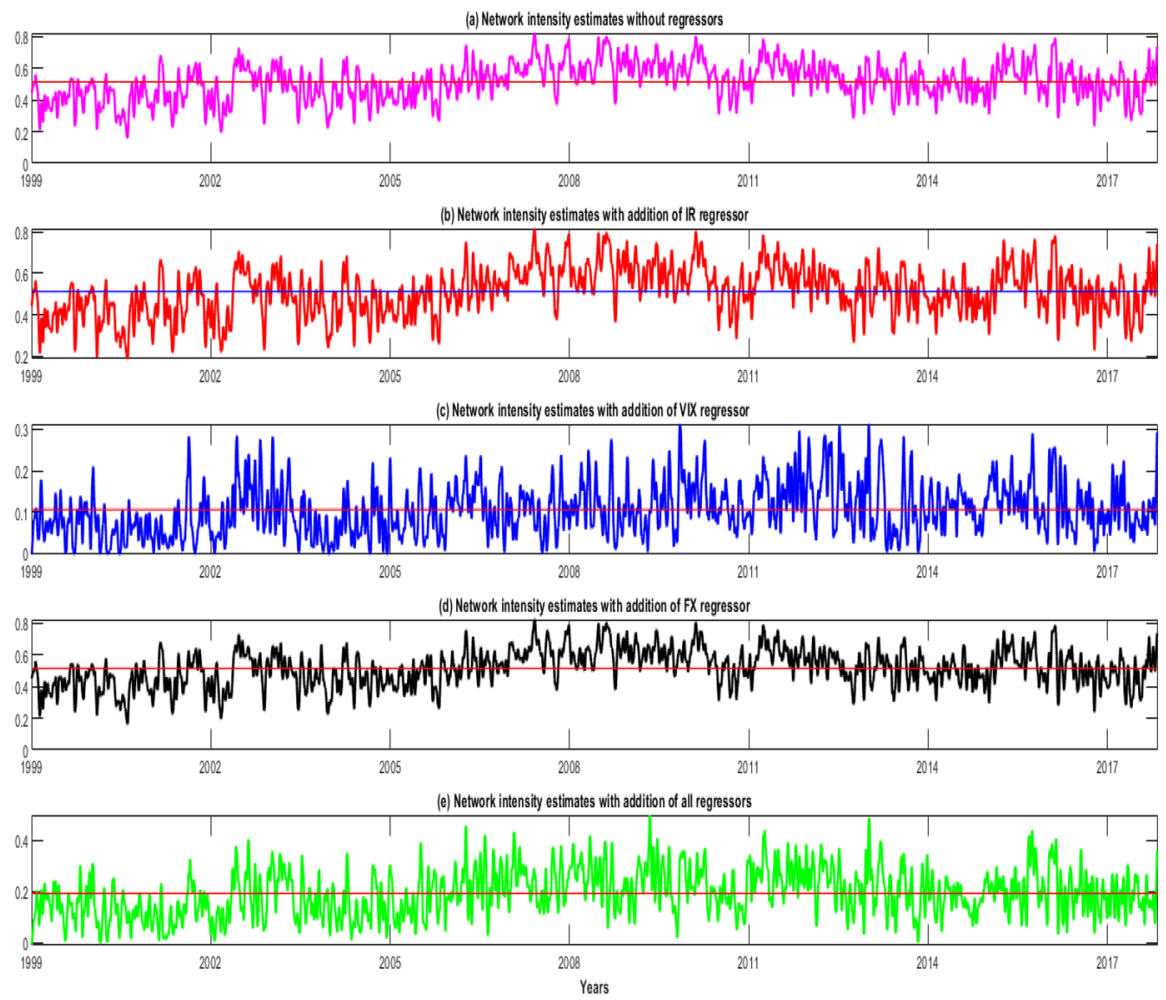

Fig. 12 Network intensity estimates with and without regressors. The figures display network effect for the entire sample period with the addition of external regressors. The horizontal line is the average estimate in the entire period. a Displays network intensity estimates without external regressors. b-d display network intensity estimates with IR, VIX and FX respectively being the external regressors. e displays network intensity estimates with all external regressors

instance VIX, dampens returns, which could result in lower network estimates. Therefore, among the external regressors, the volatility of stock market index has a greater impact on the estimation of the network intensity parameter, resulting in a $62 \%$ decrease in the estimate.

Figure 12 shows dynamic network intensity parameter, including and excluding explanatory regressors. The estimates were obtained using the dynamic SAR model specification using a 251 rolling window size.

Figure 12a displays a time-varying trend of estimate without the external regressors. The horizontal line represents the average estimate of the whole sample period. Figure 12a-d display similar patterns, while Fig. 12c and e show varying patterns. This is because while the IR and FX fluctuations either increased or decreased estimates, implied volatility (we used VIX as a proxy of implied volatility since VSTOXX provided almost identical results) of stock index had discernible effect on the estimation of network intensity parameter. Higher volatility changes the trend 
of network intensity estimates. These effects are clearly observed during the global crisis, for which the trends of Fig. 12a and c of Fig. 12 differ.

Although we can observe a similar trend in Fig. 12 (which excluded the explanatory variables), reduction of the estimated values (previously presented in Table 7) can be observed. The estimates fluctuate between 0.3 and 0.75 . This led to the same conclusion as previously discussed. The spikes in the estimates are associated with periods when the market was under stress. This is in line with Hypothesis 1. For example, the spike before 2002 is associated with the dot-com bubble, 2007-2009 with the GFC, post-2010 with the European debt crisis and 2015 with the Chinese market crash.

We now introduce additional regressors to support Hypothesis 3. Our preliminary findings showed that external factors (integration measures) have an effect on estimation. This may suggest that the financial market is highly integrated in terms of cross-border activities.

As stated in Hypothesis 2, increased interconnectedness between different markets results in increased network intensity estimates. Let us relate the horizontal line (mean value) to the period of financial system stability (robust network intensity estimate) while periods when there are spikes above the line correspond when the financial system is under stress (fragile network intensity estimate). Figure 12 depicts a robust-yet-fragile network intensity estimate. A robust-yet-fragile network would diversify small shocks, while propagating large shocks to the entire financial system, leading to distress (Acemoglu et al., 2015; Gai \& Kapadia, 2010; Tonzer, 2015). Although the network intensity was robust-yet-fragile between 2002 and 2006 (as shown in Fig. 12), the financial system benefited from risk-sharing effect. During the GFC, shocks were amplified in the financial system, causing financial instability.

\subsection{Developed versus emerging markets}

There is increasing involvement of emerging markets in enhancing financial growth and stability. Therefore, it is important to estimate the network intensity parameter for these markets and compare them with those of developed economies. The countries in our sample were classified as developed (54\%) or emerging (46\%) based on IMF 2017 classification. $^{12}$

In Table 6, we observe that developed economies have higher network intensity estimates than emerging markets. This could be due to their high inter-linkage with other markets. Schiavo et al. (2010) stated that developed economies are more interconnected to the other countries, and thus, spread shocks to other economies. Although developed markets have higher estimates than the emerging markets, emerging markets experience high fluctuations in different periods (see Fig. 8). We observe that emerging markets experienced more than a 50\% change in the estimate in Phase 2. This implies that they are largely exposed to and affected by external

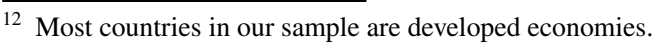




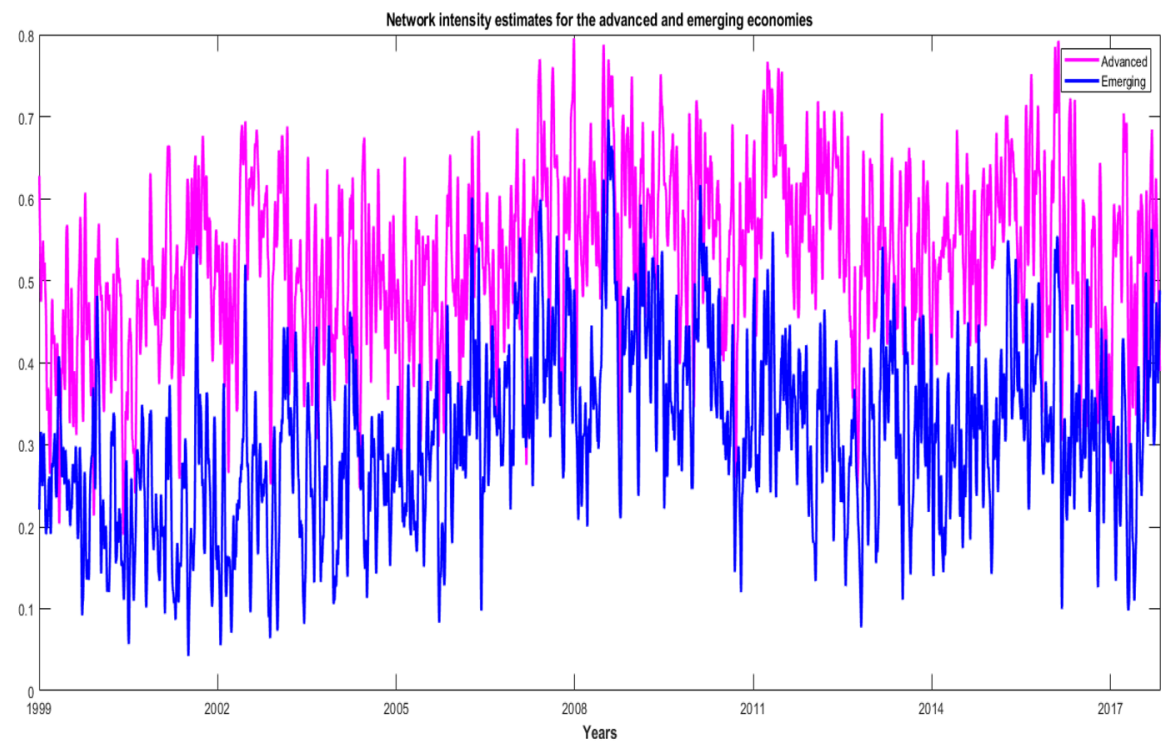

Fig. 13 Network intensity estimates for developed and emerging markets

shocks, originating from developed economies, especially in times of GFC (Aizenman et al., 2016a).

Figure 13 displays the dynamics of network intensity parameters for both developed and emerging markets. Figure 13 suggests that the dynamics of estimates for both economies differ. While the estimates of the developed markets are identical to those of the entire sample, estimates of emerging markets have different patterns. Emerging markets exhibit higher fluctuations than developed markets. This is in line with Hypothesis 4. From these results, it can be theorized that developed markets with stable economies tend to experience high network exposure, but less fluctuation. Conversely, network exposure for emerging economies varies more. Harvey (1995) suggested that this could be due to segmentation from global markets.

Our results concur with those of Aizenman et al. (2016a) - that developed markets have greater influence with higher network intensity than do emerging markets. This greater influence can be associated to developed economies being the key contributors to the GFC. That is, when a shock hit these economies through their network links, it had a greater effect on the entire economy. This finding is supported by Schiavo et al. (2010), who showed that one of the contributors of the GFC was shocks from developed markets spreading to other markets. Kubelec and Sá (2012) suggested that shocks from the US and UK (being big players in developed markets) propagated to the entire financial system during the global crisis. We identified developed economies as having many interconnections with other markets, making them more prone to risk in terms of spreading shocks to other markets. This is supported by Amini et al. (2016), who argued that institutions with large connections have a higher chance of affecting the stability of the entire system due to their link structures. Aizenman et al. (2016b) also argued that emerging markets were more 
Fig. 14 Ratio of the regional representation of the financial markets

\section{Ratio of subregion representation}

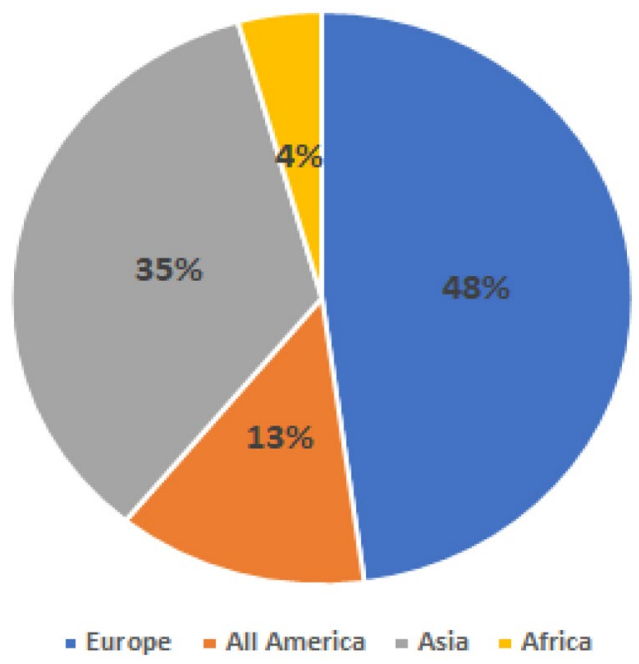

resilient during and after the GFC. Thus, developed markets played a significant role in propagating shocks to the entire financial system. This is a clear indication that policy makers should be more concerned when network intensity estimates are greater for developed markets.

Although emerging markets have lower network intensity estimates, they may also have the greatest influence in propagating shocks. We observed that emerging markets had having greater spikes especially when the market was under stress. This finding shows that emerging markets are not immune during the GFC. This suggests that emerging markets serve as hubs through which shocks from developed economies spread to the entire financial system. Aizenman et al. (2016a) also found that emerging markets were also exposed to external shocks during the GFC, especially to shocks originating in developed markets. These findings indicate that emerging markets increasingly play a role in the world economy by engaging in cross-border relationships with developed and emerging economies (Bekaert \& Harvey, 2017).

In terms of integration, we observe that developed economies with high network intensity have more cross-border activities, making the estimate higher than those of emerging markets. These results suggest that developed economies that are more stable benefit from higher network intensity. However, in the presence of shocks, these economies might have a great impact on financial stability. These findings are similar to those of Chevallier et al. (2018), who showed that developed markets play a dominant role in propagating shocks to the entire system while emerging markets are becoming more integrated with other markets. This means they can transmit shocks to other economies. These results are also supported by Schiavo et al. (2010), who found that developed economies tend to be more integrated and more clustered, resulting in larger estimates of network intensity parameters. 
Finally, developed economies network intensity estimates exhibit a robust-yetfragile feature. The financial system could benefit more from risk-sharing and diversification when small shocks hit the system. There is also a danger of large shocks being amplified throughout in the entire system, making the financial system more susceptible to collapse.

Generally, the findings suggest that developed markets are dominant in terms of high propagation of shocks to other markets compared to emerging markets (Arnold et al., 2013). This could be a result of large cross-border transactions to other markets. Although emerging markets are less dominant, they still contribute to global propagation of shocks.

\subsection{Region specific network intensity}

We investigate the evolution of network intensity parameters in different regions. From Fig. 14, all America (include both North and Latin America) represent 13\% of the total sample, Asia represents 35\% and Europe represents $48 \%$. The liability weighting matrix for each region was obtained using the combined DY and Granger causality approach. These analyses aid in investigating the extent to which network intensity parameter differs among these regions. This is in line with Hypothesis 3. Hypothesis 3 aims to investigate whether regional integration has an impact on the estimation of network intensity parameters.

Network intensity estimates in Table 6 differ for each region. On average, America has the lowest $(0.3497)$ estimate with low standard error than all other regions. The estimate is $31 \%$ lower than the original average estimate of 0.5072 . The network intensity estimate of Asia is also lower (0.3515) than the original estimate, representing a $30 \%$ decrease. Europe has the highest estimate $(0.5281)$ in the whole period, representing a $4 \%$ increase in estimate as compared from the original estimate. From Fig. 8, these estimates changed (increased or decreased) from one phase to another. For instance, these estimates increased when moving from Phase 1 to Phase 2 by more than $24 \%$ in all regions. Asia experienced a significant increase in estimates (40\% change). The estimates slightly changed (decreased) moving from Phase 2 to 3. They also changed (decreased) moving from Phase 3 to 4.

With the increasing development in the financial sector and globalization, there has been a high degree of both regional and global integration, which may be depicted in the results (Chevallier et al., 2018). The increase of crossborder transactions has led countries to become more interconnected, leading to increased financial integration between these markets. An increase in integration is be associated with increased network exposure, which tends to increase network intensity estimates (Hüser, 2015). Higher network intensity estimates in Europe signify greater integration in the European market.

Figure 15 shows the dynamic network estimates for each region. Figure 15a presents the network intensity estimates for all regions. The horizontal line is the average network intensity parameter in the whole sample. According to Fig. 15a, Europe has higher estimates than other regions. The estimates for the European 


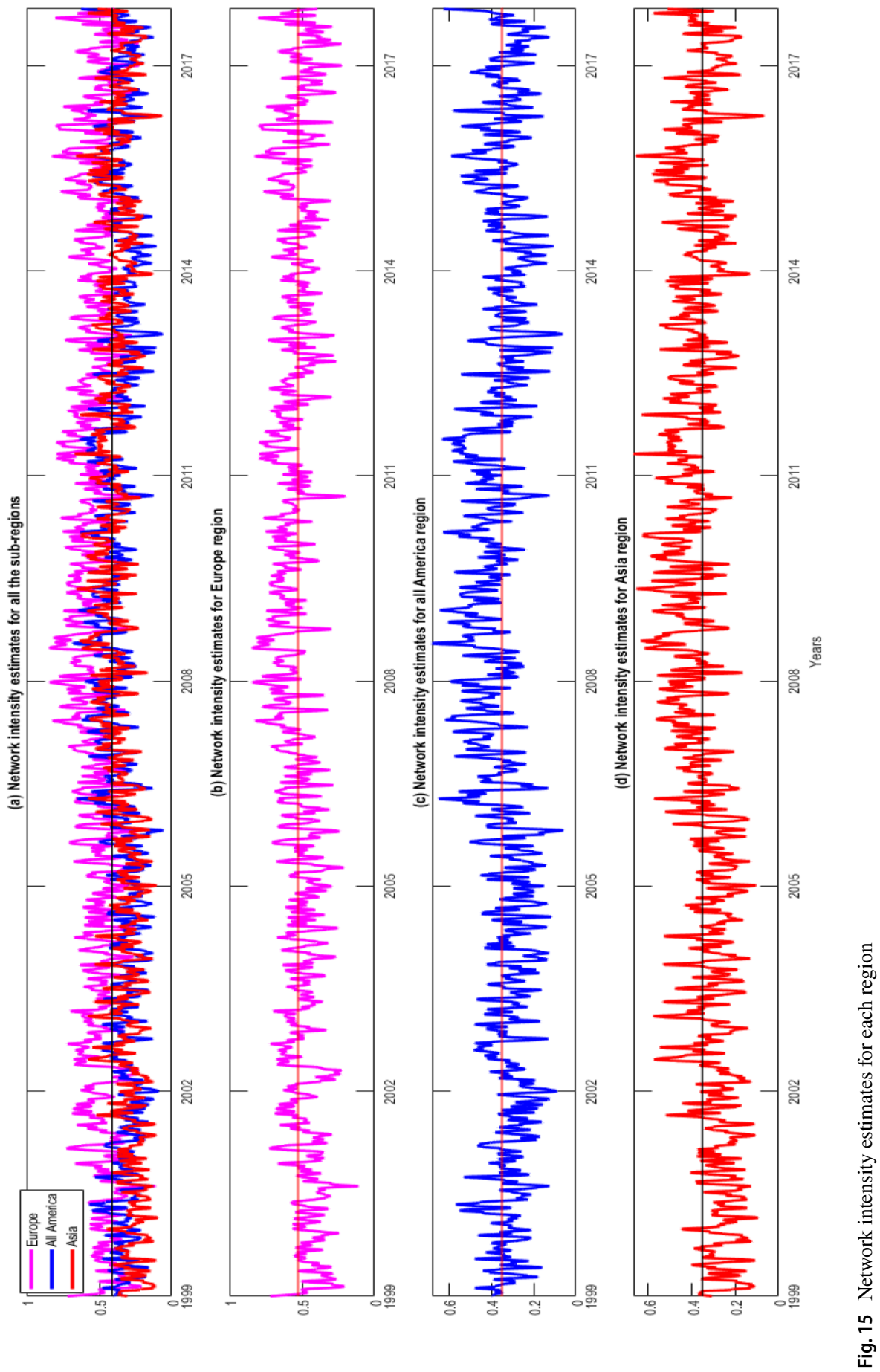


market fluctuated above the mean, while other regions, they fluctuated above and below the mean.

All America and Europe produced different patterns, suggesting that the two regions have different exposures. This could be due to different banking systems across regions, making cross-border banks from large countries (mostly the US) pose the 'too big to fail' problem. Propagation of shocks led to financial dislocation and tensions especially in the Euro areas (Belke \& Gros, 2016). Additionally, network exposure for the US and Europe would differ because the equity returns of these markets react differently to shocks. Previous literature has shown that the US had problems in banking and sovereign debt, thereby establishing a diabolical loop (Chan-Lau et al., 2015; Dufrénot \& Keddad, 2014).

For all America, we observe that network intensity estimates were higher at the beginning of the sample period and continued to decline until 2007, when the estimate fluctuate upwards. There were spikes in mid-2008, implying that propagation strength increased suddenly. The estimates fluctuated at around 0.4 before increasing to 0.6 in 2014. The presence of Latin American countries (Argentina, Brazil, Chile and Mexico) affected network intensity estimates. These emerging markets exhibited higher fluctuations in return over time.

For Europe, the opposite was true. Network intensity estimates were lower at the beginning of the sample period and then increased. Before 2012, there were spikes (the propagation strengths are higher) in network intensity estimates. They are associated with the onset of the EDC in 2010 (Mink \& De Haan, 2013). The estimates then fluctuated in an increasing trend in 2012. This suggests that European markets became more interconnected, increasing their exposures in the financial system.

The propagation strength was higher during crisis periods and remained higher during the sovereign debt crisis. This could indicate a larger impact of shock propagation, especially when a shock hits the financial system.

Conversely, the Asian region depicted a different pattern from other regions. There was a spike in 2002, and it remained higher until 2003 before dropping then fluctuates again. The estimate declined at the beginning of the crisis period before spiking in 2007. Thereafter, there is a declining trend of network intensity until hit its lowest point in 2014. The estimate remained low after 2013. These results are similar to the static estimates in Table 6. These results are consistent to those of Guimarães-Filho and Hong (2016), who argued that Asian markets are more exposed to shocks from other region, thereby increasing their exposure during crises.

Overall, the results from the regional network intensity show that exposures are high especially during crisis periods. This suggests that the fragility of the financial system tends to increase during time of stress (Sun \& Chan-Lau, 2017). This leads to financial instability.

Our findings indicate the possibility that regional network intensity estimates have an implication for policies that affect economic growth and stability. A high network intensity estimate may imply higher propagation effects from shocks to the financial system, leading to financial instability (Sun \& Chan-Lau, 2017). This aligns with Tonzer (2015), who showed that regional integration might be beneficial 
to stable economies. Therefore, by having higher network intensity, a region might benefit from diversification of shocks.

The estimates of network intensity using alternative weighting matrix are discussed in Appendix A.1. The comparison of MLE with other approaches is discussed in Appendix A.3.

\section{Implication of empirical study}

From our empirical results, we highlight why the network intensity estimate is important, especially to the financial system. We do so in an attempt to answer the questions posed below.

\subsection{Do high network intensity estimates signify spillover in the financial system?}

The changing nature of network intensity parameters raises the question of whether high or low network intensity estimates are associated with return spillover in the markets. Transmission of shocks across the financial system through different channels is known to cause financial distress. This transmission of shocks can be a result of many factors, not limited to the increasing growth of cross-border activities in the financial system.

With increasing cross-border activities over recent years, there has been a tendency for increased exposures throughout the financial system. This is depicted from our results, in which we observed that the network exposure tends to increase when the financial system is under stress. This can signify a spillover in the financial system. Moreover, increasing interactions between different markets imply high exposure to these markets in terms of risk, thereby posing a threat to the stability of the financial system. Network intensity is also affected by financial integration through cross-border flows. This in itself creates a channel of increasing spillovers in the financial system.

In general, network intensity parameters capture the strength of exposure, which relates to spillovers. We conclude, based on our results, that network intensity evolves over time and during important events. When network intensity is high, it implies that spillover is increasing in the financial system. It is worth noting that with increasing cross-border financial activities, financial institutions have become more interconnected. This has resulted in high exposure of the financial system to shocks. These results confirm that a high network intensity parameter is associated with high interconnectedness in the financial system.

\subsection{Does network intensity respond to different market conditions?}

Ever changing market conditions have led to greater complexity in the financial sector. Recent studies have revealed increased co-movements of cross-border activities. This means that with favorable market conditions the financial market has become 
more integrated. A natural question to ask is whether the different market conditions increase the chance of vulnerability in the financial sector.

For example, FX volatility may have a positive influence on network intensity estimate. This is reflected in our results, in which we observed high network intensity corresponding to periods of high volatility in FX rates.

Implied volatility used to capture overall market riskiness is expected to have a positive influence on network intensity estimates. With increasing uncertainty in the market, financial sectors are at a higher risk of failure. Our results show the considerable impact of implied volatility on network intensity estimates. All this suggests that with changing market conditions, there is an increased possibility of high network intensity, and thus, a possibility of stress in the financial system.

\section{Conclusion}

This paper investigates the dynamics of the network intensity parameter that monitors network exposure. To be specific, this paper produces two empirical findings on how network exposure contribute to increasing vulnerability in the financial system. We examine the impact of network exposure on common factors. Our findings show that both the network intensity coefficient and interconnectedness increase exposure to common factors.

We also extended our work to estimate a dynamic network intensity parameter to determine whether a high network intensity is associated with period of extreme events. Our findings suggest that a high network intensity coefficient is associated with extreme events that are related to period of distress in the financial system. The size of the network intensity coefficient serves as an indicator of stress events and could be useful in monitoring the financial system, ultimately promoting financial stability.

These findings highlight the importance of network exposure by showing the extent to which financial systems are exposed to shocks from existing linkages. Overall, the results suggest the changing market conditions increases the exposures to the financial system. Caution must be taken to monitor these exposures in order to reduce the transmission impact of these shocks.

These findings have important policy implications. Caution must be taken to monitor these exposures in order to reduce the transmission impact of these shocks. Improving regulations of the financial system can help reduce the adverse effects of network exposures in the financial system. 

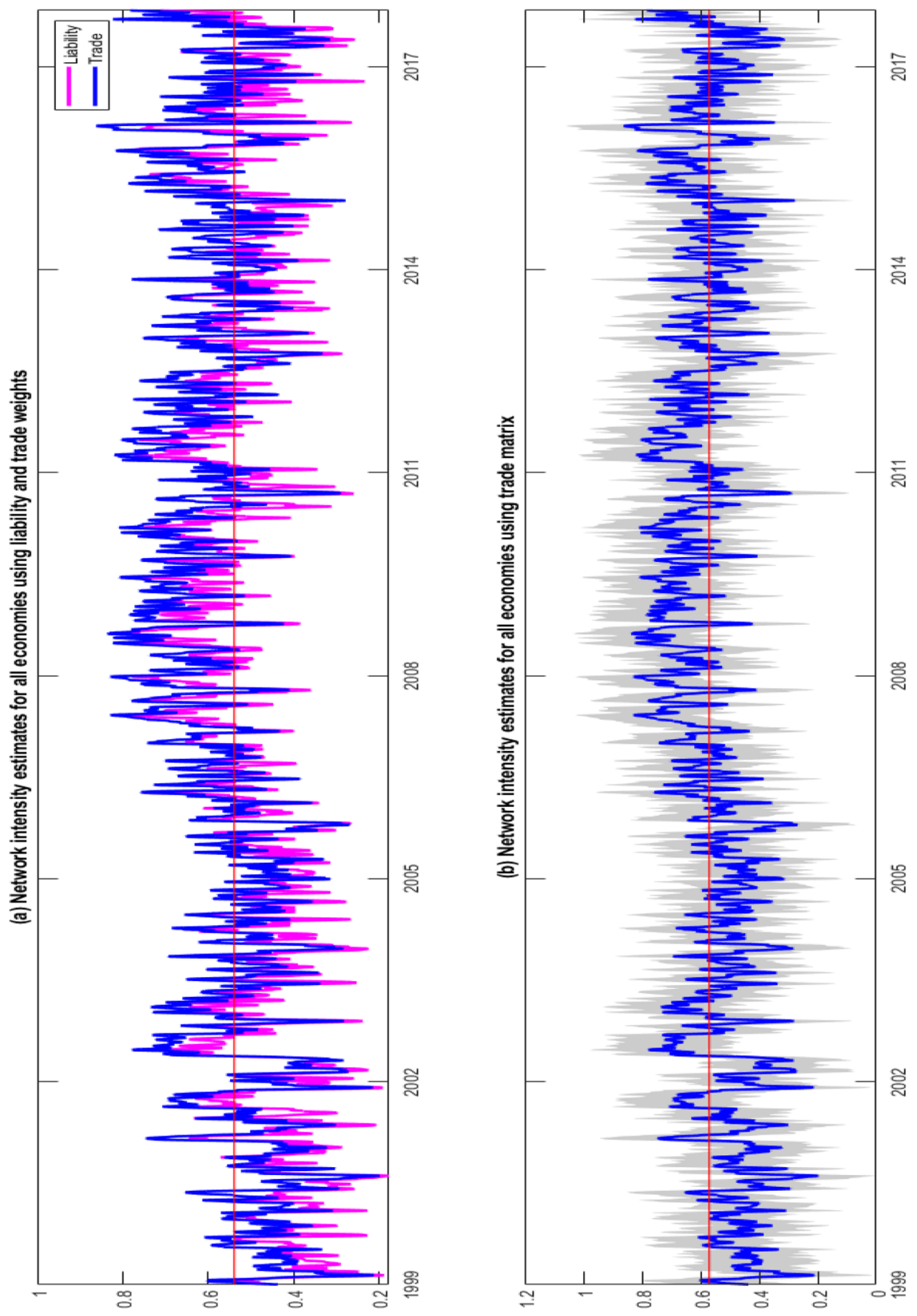
Fig. 16 Network intensity estimates based on trade and liability matrix. The figures compare the network effect using both liability and trade connection matrices for the whole sample period

\section{Appendix}

\section{Network intensity using alternative weighting matrix}

Here, we investigate the role of weighting matrix in estimating network intensity parameters. We consider the first difference of trade data to construct an alternative weighting matrix. This matrix is then used to estimate network intensity coefficients. Our data comprise of quarterly export and import data from the international monetary fund (IMF), world economic outlook (WEO) database for the selected economies. Both indirect and direct trade linkages acted as channels through which shock was transmitted in the financial system. Trade linkages represent high trade exposures in the financial system. For instance, Kali and Reyes (2010) reported that a shock is amplified in the system when financial institutions are more integrated in terms of trade linkages. Asgharian et al. (2013) found that linkages through bilateral trade capture dependencies between stock markets. This is due to feedback effects among financial markets. This suggests that trade concentration is one of the important channels through which shocks spread in the financial system.

In Fig. 16b, we present the network intensity estimates based on trade weighting matrix. The horizontal red line represents the mean value (0.5698) in the whole sample period while the shaded area is the $95 \%$ confident interval. These results show that higher network intensity estimates were associated with periods when financial systems were under stress. For instance, higher network intensity in 2002 corresponded with the dot-com bubbles while there was sharp decrease in the estimate in 2003. The estimate then fluctuate upwards and decreased just before the global crisis. There is a sharp increase in the estimate during the GFC. The estimates remain higher after the global financial crisis. A network intensity above $65 \%$ at the end of the sample period signifies a high risk of collapse when a shock hit the financial system. As can be observed in Fig. 16b, network intensity increases when a shock hit the financial system and decreased in normal periods. This supports our conclusion that a sharp increase in network intensity signals that the financial system is in distress. This observation would help regulators and policy makers monitor these financial institutions.

\section{Comparison of estimates using both liability and trade weights}

Figure 16a depicts the role of the weighting matrix in estimating the network intensity parameter. The horizontal line is the mean value of the estimate obtained using both trade and liability weighting matrix in the whole sample. These results reveal that the trade weighting matrix contributed to the upwards shift of the weighting 
matrix from 0.5149 to 0.5698 . This also implies that the mean value of the estimate is 0.5698 using trade weight matrix and 0.5149 when the liability weighting matrix is used.

The connection matrix play an important role in the estimation of the network intensity parameter. From Fig. 16a, it is clear that although the weighting matrix results in estimates with almost similar trends, their sizes differ in both cases. The network intensity estimates based on trade weights were higher than those obtained using the liability weighting matrix. This suggests that shocks through trade linkages would be more sensitive to the economy compared to those from liability linkages. This supports the fact that the strength of trade linkages increase due to bilateral trade among different markets. The patterns of network intensity estimate also differed at different points in time. For example, the network intensity obtained using trade weights increased before the dot-com bubbles, while network intensity estimated using liability data decreased.

\section{Comparison of MLE with other approaches}

Although we used the dynamic MLE approach to estimate the network intensity parameter, we also explored a state-space approach. A state-space model describes the dynamics of a latent state and how the data relate to this state. A general SAR model can be represented in a state-space form with observation and state evolution respectively as:

Observation equation:

$$
y_{t}=C \rho_{t} W y_{t}+D X_{t}+v_{t}, \quad v_{t} \sim N\left(0, V_{t}\right)
$$

State equation:

$$
p_{t}=c_{1}+A p_{t-1}+B X_{t-1}+w_{t-1}, \quad w_{t-1} \sim N\left(0, W_{t-1}\right) \quad \text { and } \quad t=1,2, \ldots, T
$$

where $A_{t}, B_{t}$ and $D_{t}$ are the input variables and $C_{t}$ is the state loading matrix. $v_{t}$ and $w_{t}$ are measurement and state space process errors respectively, $X_{t}$ is the exogenous variables. The observation equation can be expressed in matrix form as

$$
\left[\begin{array}{l}
X_{t} \\
y_{t}
\end{array}\right]=\left[\begin{array}{cc}
0 & 0 \\
D_{t} & C_{t}
\end{array}\right]\left[\begin{array}{c}
X_{t} \\
\rho_{t} W y_{t}
\end{array}\right]+\left[\begin{array}{c}
0 \\
v_{t}
\end{array}\right]
$$

while the state equation can be represented as

$$
\left[\begin{array}{l}
X_{t} \\
p_{t}
\end{array}\right]=\left[\begin{array}{cc}
0 & 0 \\
B_{t-1} & A_{t-1}
\end{array}\right]\left[\begin{array}{l}
w_{t-1} \\
p_{t-1}
\end{array}\right]+\left[\begin{array}{c}
0 \\
w_{t-1}
\end{array}\right]
$$

Figure 17 shows the network intensity estimates obtained using a Kalman filter. These estimates support our previous findings in Fig. 9a, which showed that the network intensity remained higher during periods of stress. This explains the high exposure of financial markets during difficult times. Caution is required to correctly 


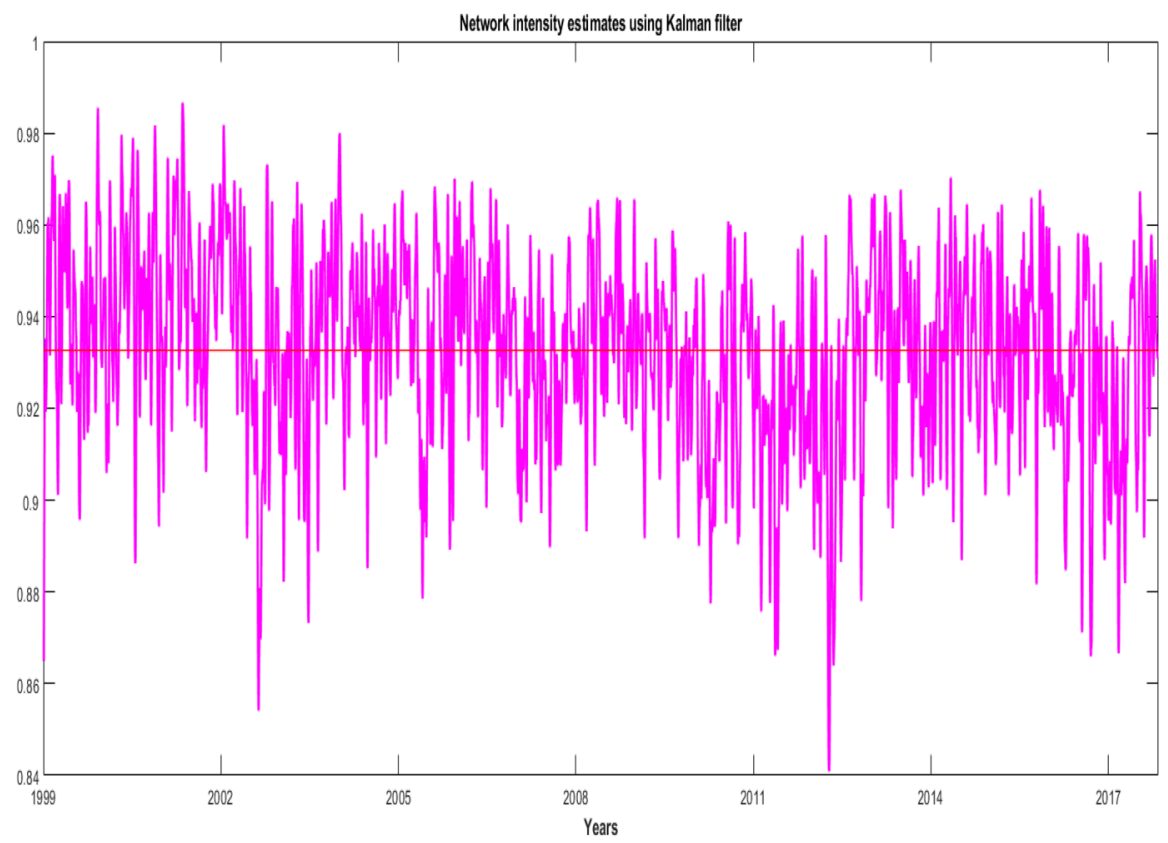

Fig. 17 Network intensity estimates using Kalman filter

monitor markets during periods of stress, which correspond with increased fragility in the financial system (Sun \& Chan-Lau, 2017).

\section{Dynamics of network intensity parameter}

We simulate 4956 daily data (the estimate choice is based on the number of sample size in our analysis) using different specifications of the spatial coefficient. These patterns are similar to Brownlees and Engle (2016) and follow:

- constant: $\rho_{t}=0.5$

- sine: $\rho_{t}==0.5+0.4 * \cos (2 * p i * k / 200)$

- fast sine: $\rho_{t}=0.5+0.4 * \cos (2 * p i * k / 20)$

- step: $\rho_{t}=0.9-0.5 *(k>500)$

All these specifications give different patterns of the network intensity parameter. Using these different specifications will help to investigate whether the initial values of the network intensity parameter matter in the estimation. Figure 18 shows these forms of network intensity parameters. The results show that network intensity parameters have different forms of changes. The constant shows a constant trend, Sine shows exhibit gradual change, and the fast sine has rapid change while step changes in different steps. 

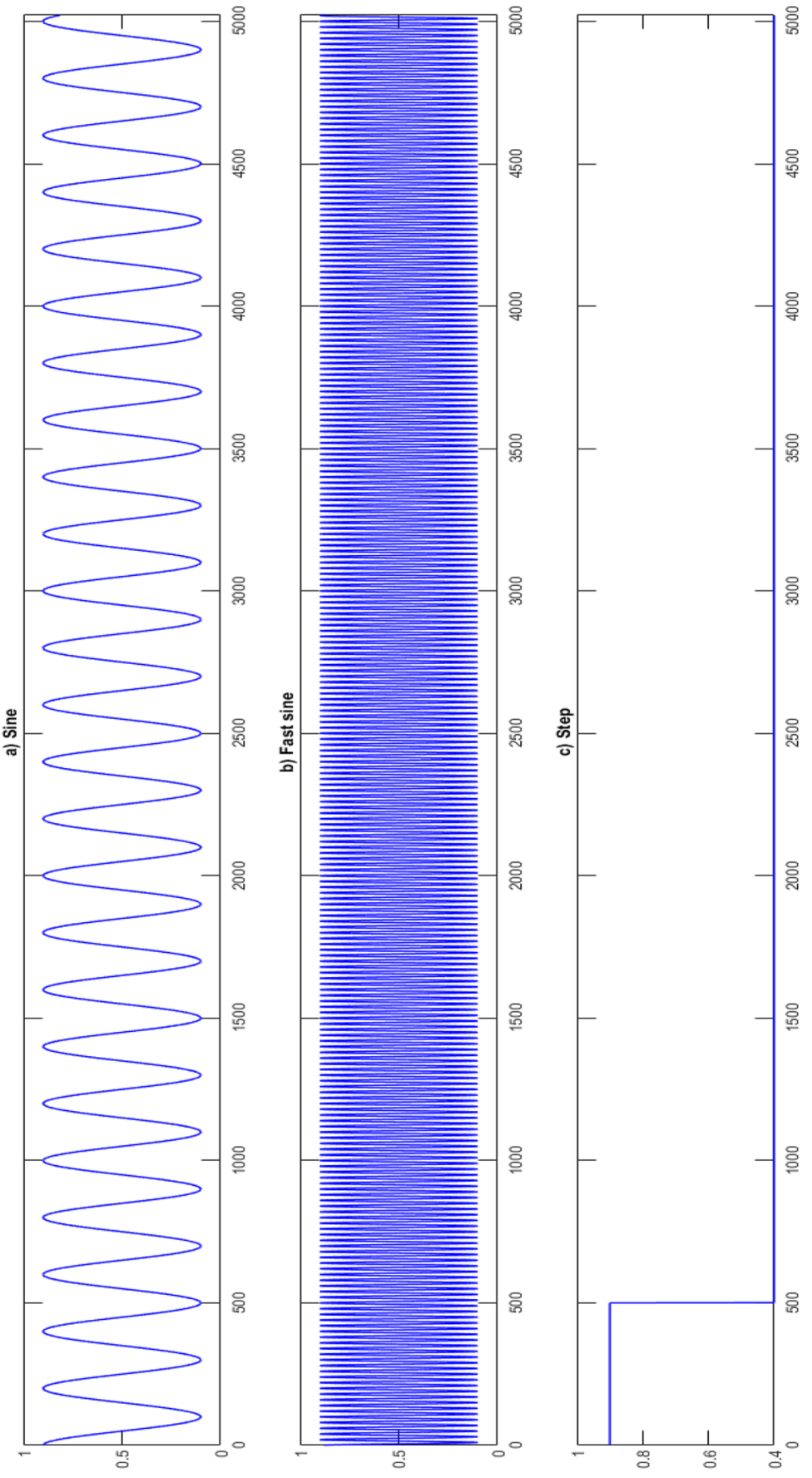

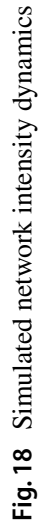


Funding Open Access funding enabled and organized by CAUL and its Member Institutions. The authors have not disclosed any funding.

\section{Declarations}

Conflict of interest On behalf of all authors, the corresponding author states that there is no conflict of interest.

Open Access This article is licensed under a Creative Commons Attribution 4.0 International License, which permits use, sharing, adaptation, distribution and reproduction in any medium or format, as long as you give appropriate credit to the original author(s) and the source, provide a link to the Creative Commons licence, and indicate if changes were made. The images or other third party material in this article are included in the article's Creative Commons licence, unless indicated otherwise in a credit line to the material. If material is not included in the article's Creative Commons licence and your intended use is not permitted by statutory regulation or exceeds the permitted use, you will need to obtain permission directly from the copyright holder. To view a copy of this licence, visit http://creativecommons.org/licen ses/by/4.0/.

\section{References}

Acemoglu, D., Ozdaglar, A., \& Tahbaz-Salehi, A. (2015). Systemic risk and stability in financial networks. American Economic Review, 105(2), 564-608.

Affinito, M., \& Pozzolo, A. F. (2017). The interbank network across the global financial crisis: Evidence from Italy. Journal of Banking \& Finance, 80, 90-107.

Aizenman, J., Jinjarak, Y., Lee, M., \& Park, D. (2016). Developing countries' financial vulnerability to the Eurozone crisis: An event study of equity and bond markets. Journal of Economic Policy Reform, 19(1), 1-19.

Aizenman, J., Jinjarak, Y., \& Park, D. (2016). Fundamentals and sovereign risk of emerging markets. Pacific Economic Review, 21(2), 151-177.

Allen, F., \& Gale, D. (2000). Financial contagion. Journal of Political Economy, 108(1), 1-33.

Alter, A., \& Beyer, A. (2014). The dynamics of spillover effects during the European sovereign debt turmoil. Journal of Banking \& Finance, 42, 134-153.

Amini, H., Cont, R., \& Minca, A. (2016). Resilience to contagion in financial networks. Mathematical Finance, 26(2), 329-365.

Anselin, L. (1988). Spatial econometrics: Methods and models. Boston: Kluwer Academic Publishers.

Antonakakis, N., Chatziantoniou, I., \& Filis, G. (2013). Dynamic co-movements of stock market returns, implied volatility and policy uncertainty. Economics Letters, 120(1), 87-92.

Apostolakis, G., \& Papadopoulos, A. P. (2014). Financial stress spillovers in advanced economies. Journal of International Financial Markets, Institutions and Money, 32, 128-149.

Arnold, M., Stahlberg, S., \& Wied, D. (2013). Modeling different kinds of spatial dependence in stock returns. Empirical Economics, 44(2), 761-774.

Asgharian, H., Hess, W., \& Liu, L. (2013). A spatial analysis of international stock market linkages. Journal of Banking \& Finance, 37(12), 4738-4754.

Bali, T. G., \& Cakici, N. (2008). Idiosyncratic volatility and the cross section of expected returns. Journal of Financial and Quantitative Analysis, 43(1), 29-58.

Bali, T. G., \& Cakici, N. (2010). World market risk, country-specific risk and expected returns in international stock markets. Journal of Banking \& Finance, 34(6), 1152-1165.

Battiston, S., \& Caldarelli, G. (2013). Systemic risk in financial networks. Journal of Financial Management, Markets and Institutions, 1(2), 129-154.

Battiston, S., Gatti, D. D., Gallegati, M., Greenwald, B., \& Stiglitz, J. E. (2012). Liaisons dangereuses: Increasing connectivity, risk sharing and systemic risk. Journal of Economic Dynamics and Control, 36(8), 1121-1141. 
Bekaert, G., \& Harvey, C. R. (2017). Emerging equity markets in a globalising world. Available at SSRN 2344817.

Belke, A., \& Gros, D. (2016). On the shock-absorbing properties of a banking union: Europe compared with the United States. Comparative Economic Studies, 58(3), 359-386.

Billio, M., Caporin, M., Panzica, R., \& Pelizzon, L. (2015). Network connectivity and systematic risk. Working Paper.

Billio, M., Getmansky, M., Lo, A. W., \& Pelizzon, L. (2010). Measuring systemic risk in the finance and insurance sectors. MIT Sloan School Working Paper.

Billio, M., Getmansky, M., Lo, A. W., \& Pelizzon, L. (2012). Econometric measures of connectedness and systemic risk in the finance and insurance sectors. Journal of Financial Economics, 104(3), 535-559.

Black, L., Correa, R., Huang, X., \& Zhou, H. (2016). The systemic risk of European banks during the financial and sovereign debt crises. Journal of Banking \& Finance, 63, 107-125.

Blasques, F., Koopman, S. J., Lucas, A., \& Schaumburg, J. (2016). Spillover dynamics for systemic risk measurement using spatial financial time series models. Journal of Econometrics, 195(2), 211-223.

Brownlees, C., \& Engle, R. F. (2016). SRISK: A conditional capital shortfall measure of systemic risk. Review of Financial Studies, 30(1), 48-79.

Bruno, V., \& Shin, H. S. (2014). Cross-border banking and global liquidity. The Review of Economic Studies, 82(2), 535-564.

Cai, J., Saunders, A., \& Steffen, S. (2014). Syndication, interconnectedness and systemic risk. ESMT European School of Management and Technology.

Campbell, J. Y., Lettau, M., Malkiel, B. G., \& Yexiao, X. (2001). Have individual stocks become more volatile? An empirical exploration of idiosyncratic risk. The Journal of Finance, 56(1), 1-43.

Cao, Y., Gregory-Smith, I., \& Montagnoli, A. (2017). Transmission of liquidity shocks: Evidence on cross-border bank ownership linkages. Journal of International Financial Markets, Institutions and Money, 53, 158-178.

Catania, L., \& Billé, A. G. (2017). Dynamic spatial autoregressive models with autoregressive and heteroskedastic disturbances. Journal of Applied Econometrics, 32(6), 1178-1196.

Chan-Lau, J. A., Liu, E. X., \& Schmittmann, J. M. (2015). Equity returns in the banking sector in the wake of the great recession and the European sovereign debt crisis. Journal of Financial Stability, $16,164-172$.

Chevallier, J., Nguyen, D. K., Siverskog, J., \& Uddin, G. S. (2018). Market integration and financial linkages among stock markets in Pacific Basin countries. Journal of Empirical Finance, 46, 77-92.

Chowdhury, B., Dungey, M., Kangogo, M., Abu Sayeed, M., \& Volkov, V. (2019). The changing network of financial market linkages: The Asian experience. International Review of Financial Analysis, 64, 71-92.

Cohen-Cole, E., Patacchini, E., \& Zenou, Y. (2012). Systemic risk and network formation in the interbank market. CAREFIN Research Paper No. 25/2010.

Degiannakis, S., Filis, G., \& Hassani, H. (2018). Forecasting global stock market implied volatility indices. Journal of Empirical Finance, 46, 111-129.

Diebold, F. X., \& Yilmaz, K. (2013). Measuring the dynamics of global business cycle connectedness. PIER Working Paper.

Diebold, F. X., \& Yilmaz, K. (2009). Measuring financial asset return and volatility spillovers, with application to global equity markets. The Economic Journal, 119(534), 158-171.

Diebold, F. X., \& Yilmaz, K. (2012). Better to give than to receive: Predictive directional measurement of volatility spillovers. International Journal of Forecasting, 28(1), 57-66.

Dufrénot, G., \& Keddad, B. (2014). Spillover effects of the 2008 global financial crisis on the volatility of the Indian equity markets: Coupling or uncoupling? A study on sector-based data. International Review of Financial Analysis, 33, 17-32.

Dungey, M., Luciani, M., \& Veredas, D. (2012). Ranking systemically important financial institutions. Tinbergen Institute Discussion Paper.

Dungey, M., Milunovich, G., Thorp, S., \& Yang, M. (2015). Endogenous crisis dating and contagion using smooth transition structural GARCH. Journal of Banking \& Finance, 58, 71-79.

Dungey, M., \& Renault, E. (2018). Identifying contagion. Journal of Applied Econometrics, 33(2), 227-250.

Eder, A., \& Keiler, S. (2015). CDS spreads and contagion amongst systemically important financial institutions: A spatial econometric approach. International Journal of Finance \& Economics, 20(4), 291-309. 
Edwards, S., et al. (1998). Interest rate volatility, contagion and convergence: An empirical investigation of the cases of Argentina, Chile and Mexico. Journal of Applied Economics, 1(1), 55-86.

Elhorst, J. P. (2010). Applied spatial econometrics: Raising the bar. Spatial Economic Analysis, 5(1), 9-28.

Engle, R. (2002). Dynamic conditional correlation: A simple class of multivariate generalised autoregressive conditional heteroskedasticity models. Journal of Business \& Economic Statistics, 20(3), $339-350$.

Fernandez, V. (2011). Spatial linkages in international financial markets. Quantitative Finance, 11(2), 237-245.

Flood, R. P., \& Garber, P. M. (1984). Collapsing exchange-rate regimes: Some linear examples. Journal of International Economics, 17(1-2), 1-13.

Forbes, K. J., \& Rigobon, R. (2002). No contagion, only interdependence: Measuring stock market comovements. The Journal of Finance, 57(5), 2223-2261.

Frankel, J. A., \& Rose, A. K. (1996). Currency crashes in emerging markets: An empirical treatment. Journal of international Economics, 41(3-4), 351-366.

Gai, P., \& Kapadia, S. (2010). Contagion in financial networks. Proceedings of the Royal Society A: Mathematical, Physical and Engineering Sciences, 466(2120), 2401-2423.

Geraci, M. V., \& Gnabo, J.-Y. (2018). Measuring interconnectedness between financial institutions with Bayesian time-varying vector autoregressions. Journal of Financial and Quantitative Analysis, 53(3), 1371-1390.

Giudici, P., Leach, T., \& Pagnottoni, P. (2021). Libra or librae? Basket based stablecoins to mitigate foreign exchange volatility spillovers. Finance Research Letters, 44, 102054.

Giudici, P., \& Pagnottoni, P. (2019). High frequency price change spillovers in bitcoin markets. Risks, 7(4), 111.

Giudici, P., \& Pagnottoni, P. (2020). Vector error correction models to measure connectedness of bitcoin exchange markets. Applied Stochastic Models in Business and Industry, 36(1), 95-109.

Glasserman, P., \& Young, H. P. (2015). How likely is contagion in financial networks? Journal of Banking \& Finance, 50, 383-399.

Glasserman, P., \& Young, H. P. (2016). Contagion in financial networks. Journal of Economic Literature, 54(3), 779-831.

Gofman, M. (2017). Efficiency and stability of a financial architecture with too-interconnected-to-fail institutions. Journal of Financial Economics, 124(1), 113-146.

González-Páramo, J. M. (2010). Globalisation, international financial integration and the financial crisis-the future of european and international financial market regulation and supervision. Discurso en el Institute of International and European Affairs.

Guimarães-Filho, R., \& Hong, G. H. (2016). Dynamic connectedness of Asian equity markets. IMF Working Paper WP/16/57.

Haldane, A. (2009). Rethinking the financial network. Speech delivered at the Financial Students Association, 28 April 2009, Amsterdam.

Harvey, C. R. (1995). Predictable risk and returns in emerging markets. The Review of Financial Studies, $8(3), 773-816$.

Hautsch, N., Schaumburg, J., \& Schienle, M. (2014). Financial network systemic risk contributions. Review of Finance, 19(2), 685-738.

Hueng, C. J., \& Yau, R. (2013). Country-specific idiosyncratic risk and global equity index returns. International Review of Economics \& Finance, 25, 326-337.

Hung, N. T. (2021). Financial connectedness of gcc emerging stock markets. Eurasian Economic Review, 11(4), 753-773.

Hüser, A.-C. (2015). Too interconnected to fail: A survey of the interbank networks literature. SAFE Working Paper No. 91.

Kali, R., \& Reyes, J. (2010). Financial contagion on the international trade network. Economic Inquiry, 48(4), 1072-1101.

Kleimeier, S., Lehnert, T., \& Verschoor, W. F. C. (2008). Measuring financial contagion using timealigned data: The importance of the speed of transmission of shocks. Oxford Bulletin of Economics and Statistics, 70(4), 493-508.

Krugman, P. (1979). A model of balance-of-payments crises. Journal of Money, Credit and Banking, 11(3), 311-325.

Kubelec, C., \& Sá, F. (2012). The geographical composition of national external balance sheets: 19802005. International Journal of Central Banking, 8(2), 143-189. 
Lee, L.-F. (2002). Consistency and efficiency of least squares estimation for mixed regressive, spatial autoregressive models. Econometric Theory, 18(2), 252-277.

Lee, L. (2007). GMM and 2 SLS estimation of mixed regressive, spatial autoregressive models. Journal of Econometrics, 137(2), 489-514.

LeSage, J., \& Pace, R. K. (2009). Introduction to spatial econometrics. Chapman and Hall/CRC.

Lintner, J. (1965). The valuation of in stock portfolios and capital budgets. The Review of Economics and Statistics, 47(1), 13-37.

Markose, S., Giansante, S., \& Shaghaghi, A. R. (2012). Too interconnected to fail' financial network of US CDS market: Topological fragility and systemic risk. Journal of Economic Behavior \& Organization, 83(3), 627-646.

Mink, M. (2015). Measuring stock market contagion: Local or common currency returns? Emerging Markets Review, 22, 18-24.

Mink, M., \& De Haan, J. (2013). Contagion during the Greek sovereign debt crisis. Journal of International Money and Finance, 34, 102-113.

Minoiu, C., \& Sharma, S. (2014). Financial networks key to understanding systemic risk. IMF Survey Magazine.

Minoiu, C., Kang, C., Subrahmanian, V. S., \& Berea, A. (2015). Does financial connectedness predict crises? Quantitative Finance, 15(4), 607-624.

Minoiu, C., \& Reyes, J. A. (2013). A network analysis of global banking: 1978 - 2010. Journal of Financial Stability, 9(2), 168-184.

Narayan, P. K., Narayan, S., \& Prabheesh, K. P. (2014). Stock returns, mutual fund flows and spillover shocks. Pacific-Basin Finance Journal, 29, 146-162.

Peltonen, T. A., Rancan, M., \& Sarlin, P. (2019). Interconnectedness of the banking sector as a vulnerability to crises. International Journal of Finance \& Economics, 24(2), 963-990.

Peralta, G., \& Zareei, A. (2016). A network approach to portfolio selection. Journal of Empirical Finance, 38, 157-180.

Resta, M., Pagnottoni, P., \& Giuli, M. E. D. (2020). Technical analysis on the bitcoin market: Trading opportunities or investors' pitfall? Risks, 8(2), 44.

Salant, S. W., \& Henderson, D. W. (1978). Market anticipations of government policies and the price of gold. Journal of Political Economy, 86(4), 627-648.

Schiavo, S., Reyes, J., \& Fagiolo, G. (2010). International trade and financial integration: A weighted network analysis. Quantitative Finance, 10(4), 389-399.

Sharpe, W. F. (1964). Capital asset prices: A theory of market equilibrium under conditions of risk. The Journal of Finance, 19(3), 425-442.

Silva, T. C., de Souza, S. R. S., \& Tabak, B. M. (2016). Network structure analysis of the Brazilian interbank market. Emerging Markets Review, 26, 130-152.

Spelta, A. (2017). Financial market predictability with tensor decomposition and links forecast. Applied Network Science, 2(1), 7.

Spelta, A., Flori, A., Pecora, N., \& Pammolli, F. (2021). Financial crises: Uncovering self-organized patterns and predicting stock markets instability. Journal of Business Research, 129, 736-756.

Spelta, A., Pecora, N., \& Pagnottoni, P. (2022). Chaos based portfolio selection: A nonlinear dynamics approach. Expert Systems with Applications, 188, 116055.

Sun, A. J., \& Chan-Lau, J. A. (2017). Financial networks and interconnectedness in an advanced emerging market economy. Quantitative Finance, 17(12), 1833-1858.

Tonzer, L. (2015). Cross-border interbank networks, banking risk and contagion. Journal of Financial Stability, 18, 19-32.

Vitali, S., Battiston, S., \& Gallegati, M. (2016). Financial fragility and distress propagation in a network of regions. Journal of Economic Dynamics and Control, 62, 56-75.

Wang, G.-J., Xie, C., \& Stanley, H. E. (2018). Correlation structure and evolution of world stock markets: Evidence from Pearson and partial correlation-based networks. Computational Economics, 51(3), 607-635.

Yarovaya, L., Brzeszczyński, J., \& Lau, C. K. M. (2016). Intra and inter-regional return and volatility spillovers across emerging and developed markets: Evidence from stock indices and stock index futures. International Review of Financial Analysis, 43, 96-114.

Yellen, J. L. (2013). Interconnectedness and systemic risk: Lessons from the financial crisis and policy implications: A speech at the American economic association/American finance association joint luncheon, San Diego. American Finance Association. 
Yu, H., Fang, L., Sun, B., \& Du, D. (2017). Risk contribution of the Chinese stock market to developed markets in the post-crisis period. Emerging Markets Review, 34, 87-97.

Publisher's Note Springer Nature remains neutral with regard to jurisdictional claims in published maps and institutional affiliations. 